LA W RENCE LIVERMORE NATIONAL LABORATORY
2013 LLNL Nuclear Forensics Summer Program

A. B. Kersting

September 27, 2013 
This document was prepared as an account of work sponsored by an agency of the United States government. Neither the United States government nor Lawrence Livermore National Security, LLC, nor any of their employees makes any warranty, expressed or implied, or assumes any legal liability or responsibility for the accuracy, completeness, or usefulness of any information, apparatus, product, or process disclosed, or represents that its use would not infringe privately owned rights. Reference herein to any specific commercial product, process, or service by trade name, trademark, manufacturer, or otherwise does not necessarily constitute or imply its endorsement, recommendation, or favoring by the United States government or Lawrence Livermore National Security, LLC. The views and opinions of authors expressed herein do not necessarily state or reflect those of the United States government or Lawrence Livermore National Security, LLC, and shall not be used for advertising or product endorsement purposes.

This work performed under the auspices of the U.S. Department of Energy by Lawrence Livermore National Laboratory under Contract DE-AC52-07NA27344. 


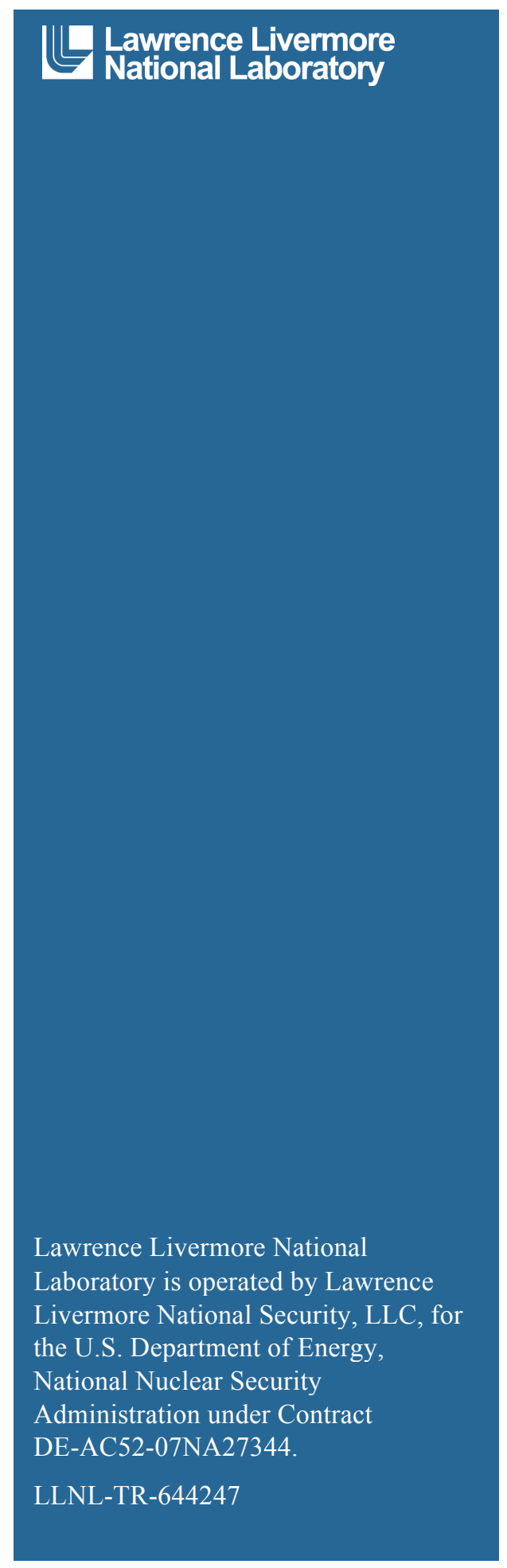

\section{LLNL Nuclear Forensics Summer Program}

Glenn T. Seaborg Institute

Lawrence Livermore National Laboratory

Physical and Life Sciences

Livermore, CA 94550

Director: Annie Kersting (kersting1@1lnl.gov)

Administrator: Camille Vandermeer

Website: https://seaborg.1lnl.gov/

Sponsors:

National Technical Nuclear Forensics Center, Domestic

Nuclear Detection Office, Department of Homeland Security

LLNL: Glenn T. Seaborg Institute, Physical and Life

Sciences Directorate

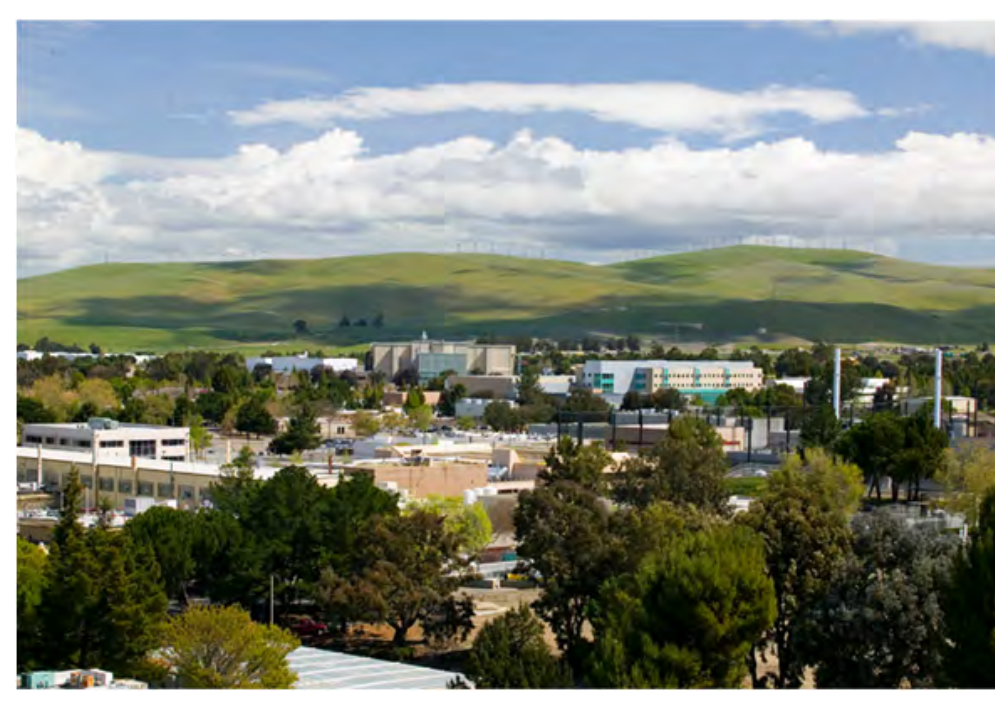




\section{Disclaimer}

This document was prepared as an account of work sponsored by an agency of the United States government. Neither the United States government nor Lawrence Livermore National Security, LLC, nor any of their employees makes any warranty, expressed or implied, or assumes any legal liability or responsibility for the accuracy, completeness, or usefulness of any information, apparatus, product, or process disclosed, or represents that its use would not infringe privately owned rights. Reference herein to any specific commercial product, process, or service by trade name, trademark, manufacturer, or otherwise does not necessarily constitute or imply its endorsement, recommendation, or favoring by the United States government or Lawrence Livermore National Security, LLC. The views and opinions of authors expressed herein do not necessarily state or reflect those of the United States government or Lawrence Livermore National Security, LLC, and shall not be used for advertising or product endorsement purposes.

\section{Auspices}

This work was performed under the auspices of the U.S. Department of Energy by Lawrence Livermore National Laboratory under Contract DE-AC52-07NA273 


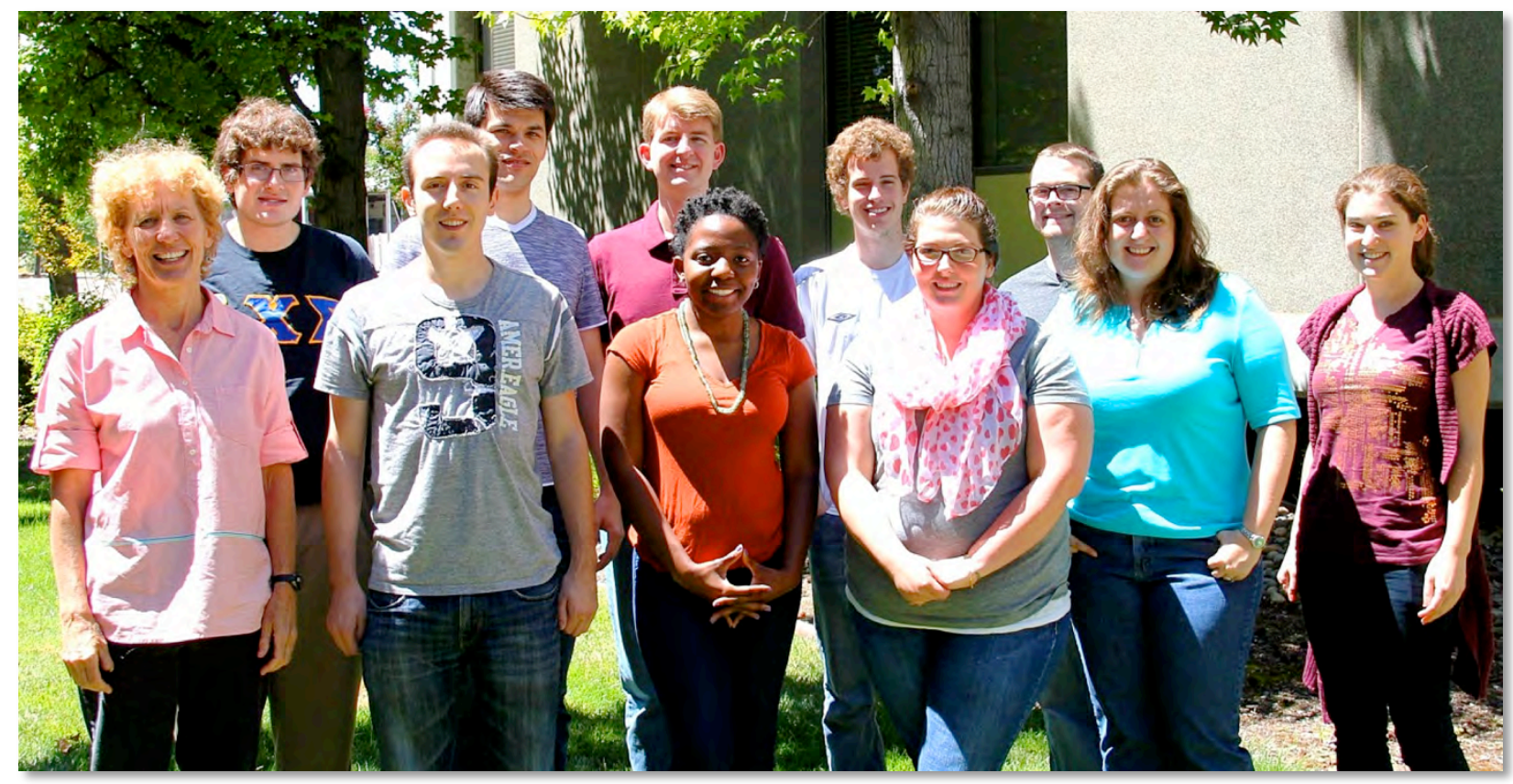

Figure 1. Annie Kersting, Director, Glenn T. Seaborg Institute (far left), and 2013 Nuclear Forensics Summer Program Students

The Lawrence Livermore National Laboratory (LLNL) Nuclear Forensics Summer Program is designed to give both undergraduate and graduate students an opportunity to come to LLNL for 8-10 weeks for a hands-on research experience. Students conduct research under the supervision of a staff scientist, attend a weekly lecture series, interact with other students, and present their work in poster format at the end of the program. Students also have the opportunity to meet staff scientists one-on-one, participate in LLNL facility tours (e.g., the National Ignition Facility and Center for Accelerator Mass Spectrometry) to gain a better understanding of the multi-disciplinary, on going science at LLNL.

Currently called the Nuclear Forensics Summer Program, this program began 13 years ago as the Actinide Sciences Summer Program. The program is run within the Glenn T. Seaborg Institute in the Physical and Life Sciences Directorate at LLNL. The goal of the Nuclear Forensics Summer Program is to facilitate the training of the next generation of nuclear scientists and engineers to solve critical national security problems in the field of nuclear forensics and have the student experience conducting research at the Lab. We select students who are majoring in physics, chemistry, geology, mathematics, nuclear engineering, chemical engineering and environmental sciences. Students engage in research projects in the disciplines of actinide chemistry, radiochemistry, isotopic analysis, computational analysis, radiation detection, and nuclear engineering in order to strengthen the "pipeline" for future scientific disciplines critical to DHS (DNDO), NNSA.

This is a competitive program with over 80 applicants for the $7-10$ slots available. Students come highly recommended from universities all over the country. For example, this year we hosted students from Texas A\&M, University of Cincinnati, Washington State University, University of Nevada, Las Vegas, and University of Missouri. (See Table 1). 
This year students conducted research on such diverse topics as actinide $(\mathrm{Np}, \mathrm{U}, \mathrm{Pu})$ isotopic fingerprinting, statistical modeling in nuclear forensics, actinide analysis for nuclear forensics, environmental radiochemistry, radiation detector materials development, coincidence counting methods, nuclear chemistry, and heavy element separations chemistry (see Table 2.) Graduate students are invited to return for a second year at their mentor's discretion. We encourage the continuation of research collaboration between graduate student, faculty advisor, and Laboratory scientists.

In addition to hands-on training, students attend a weekly lecture series on topics applicable to the field of nuclear forensics (see Table 3). Speakers are experts from both within LLNL and external to it. Speakers are able to discuss the importance of their work in the context of advances in the field of nuclear forensics.

Graduate and undergraduate students on fellowships such as the Nuclear Forensics Graduate Fellowship are invited into our summer program. They usually come for 12 weeks and can return the following summer or stay throughout the year depending on their research needs. This year we had five Nuclear Forensics Fellows, four in the graduate program and one in the undergraduate program (Table 1, noted by an asterisk).

We also host students who are participating in the DOE-sponsored "Summer School in Radiochemistry” course held at San Jose State University and have recruited from this program. They come for a day, meet our summer students, see the research our students are doing, and tour our facilities. Staff scientists also participate in the Nuclear Forensics Undergraduate Summer Program sponsored by DHS-DNDO (FY13 held at University of Nevada, Las Vegas). This year the students come to LLNL for two days to meet our summer students, learn about their research, meet the staff and learn more about work at a national laboratory.

We use our summer program to create a successful pipeline of top-quality students from universities across the U.S. Since 2002, 42 students have returned and/or conducted their graduate research at LLNL:

- 12 became postdoctoral fellows at LLNL.

- 3 became postdoctoral fellows at other national labs.

- 7 were hired as career scientists at LLNL.

- 3 were hired as career scientists at other national labs.

- 3 were hired as faculty in the area of nuclear forensics/radiochemistry/nuclear science.

A big factor in the success of this program is the dedication of the staff scientists who volunteer to mentor the summer students. In FY12, funding from the Nuclear Forensics Graduate Mentoring Program (sponsor: DNDO) helped to partially support the time staff took to teach the summer interns. Staff scientists were able to take the necessary time to develop an appropriate summer project for their student, oversee necessary safety training, and dedicate more time to helping the interns maximize their productivity and scientific potential.

The posters presented at our Laboratory Student Poster Day are included at the end of this report. Two of our students won 'best poster' award out of about 250 poster presentations. 

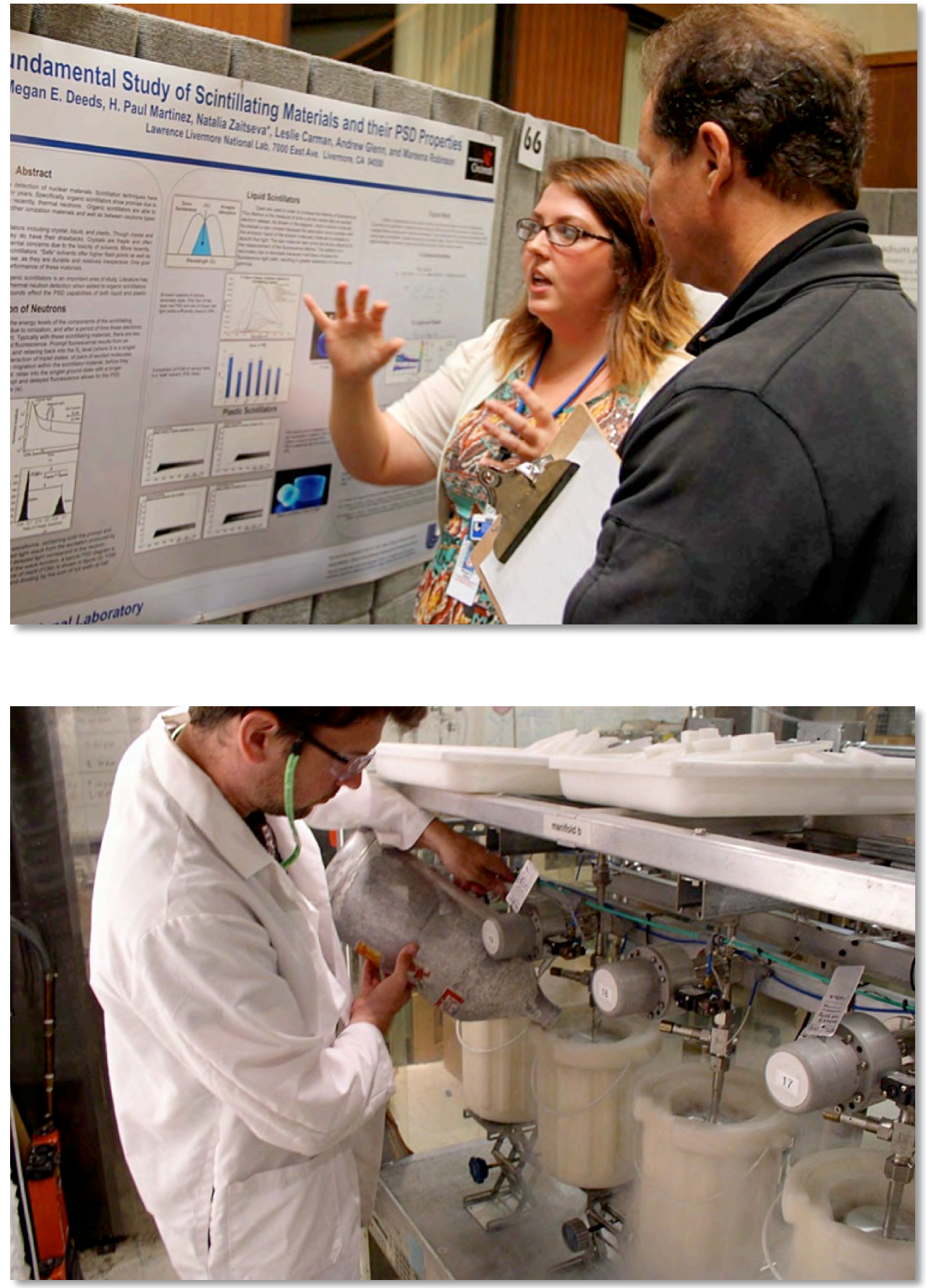

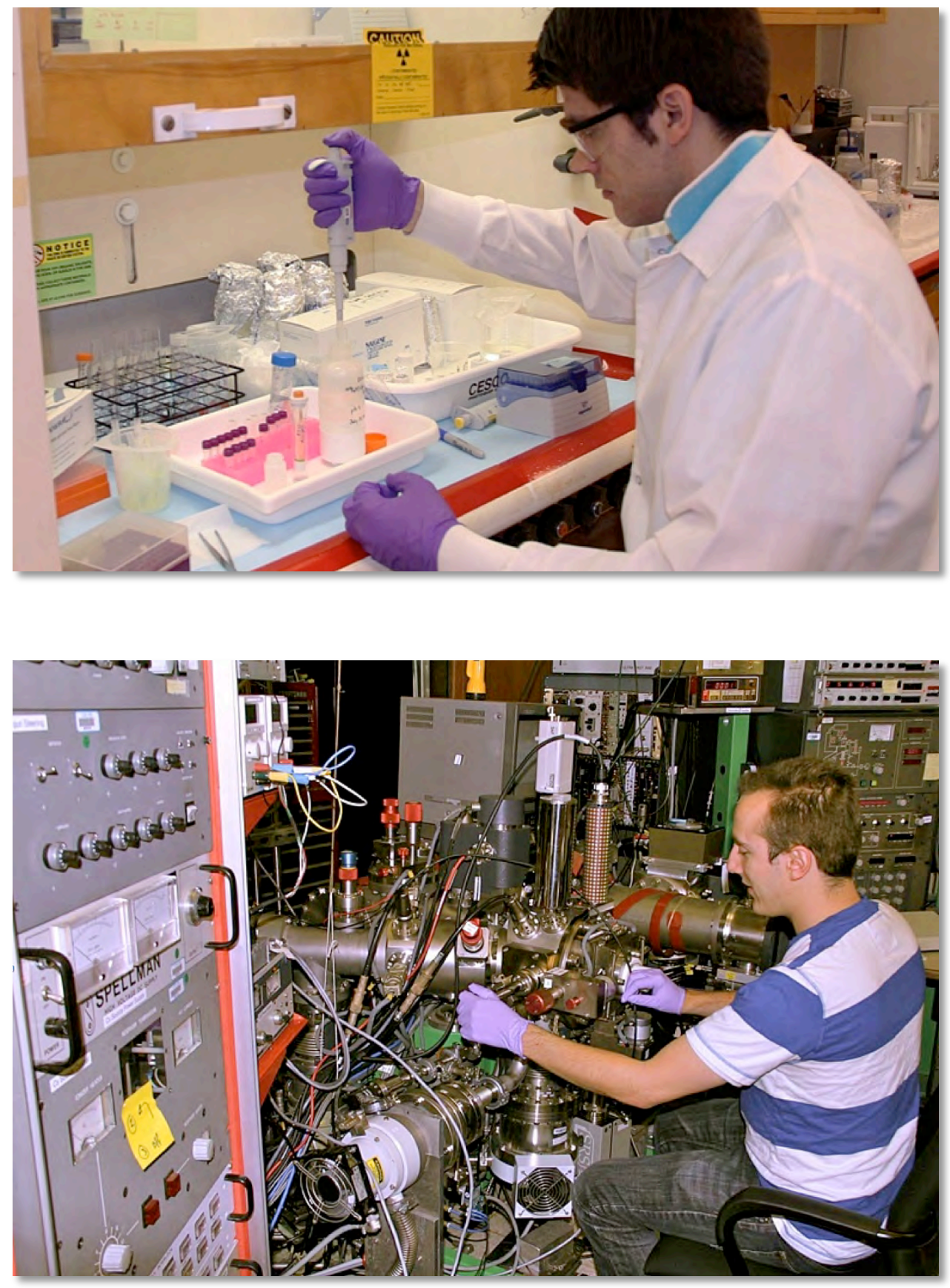

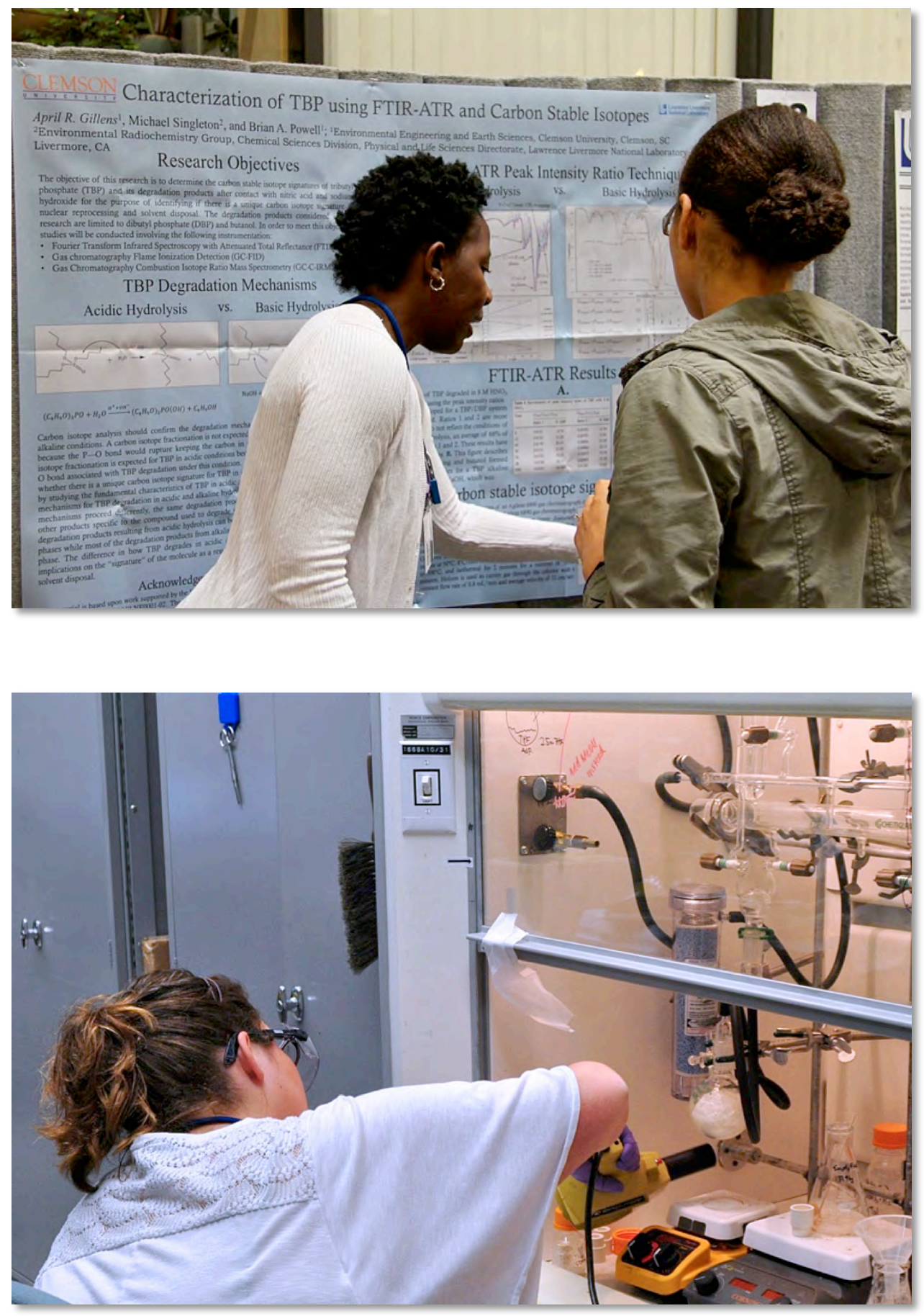


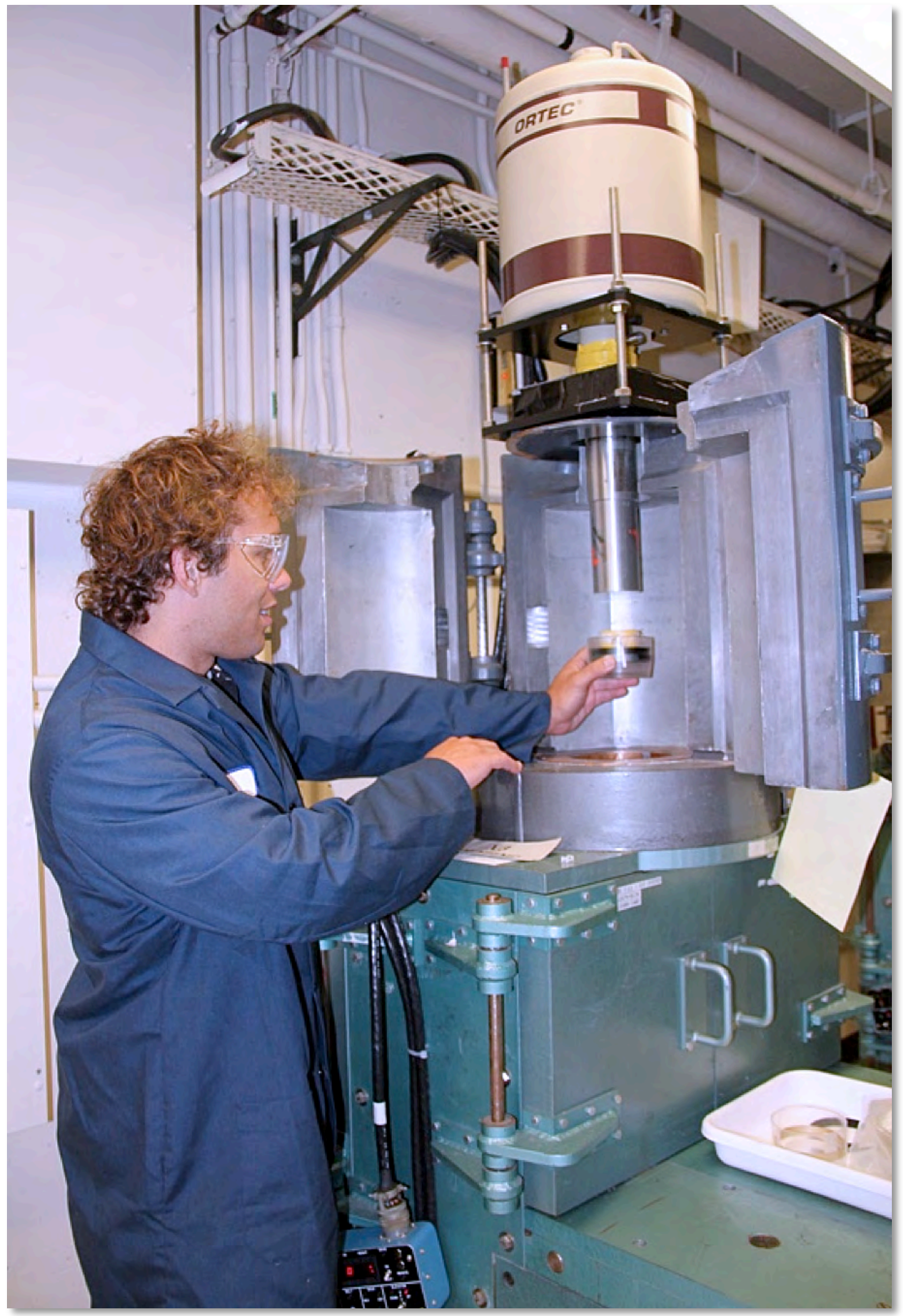


Table 1. Summer Students

\begin{tabular}{|c|c|c|c|}
\hline Student & Major & University & Year \\
\hline Marisa Alfanso & Chemistry & $\begin{array}{c}\text { Texas A\&M } \\
\text { University, } \\
\text { College Station }\end{array}$ & Grad \\
\hline Lucas Boron-Brenner & Radiochemistry & $\begin{array}{l}\text { University of Nevada, } \\
\text { Las Vegas }\end{array}$ & Grad \\
\hline Megan Deeds & Chemistry & $\begin{array}{l}\text { University of } \\
\text { Cincinnati }\end{array}$ & Grad \\
\hline Chad Durrant* & Nuclear Engineering & $\begin{array}{l}\text { The Pennsylvania } \\
\text { State University }\end{array}$ & Grad \\
\hline Marc Fitzgerald* & Chemistry & $\begin{array}{c}\text { University of Nevada, } \\
\text { Las Vegas }\end{array}$ & Grad \\
\hline April Gillens* & $\begin{array}{c}\text { Environmental } \\
\text { Engineering and Earth } \\
\text { Sciences }\end{array}$ & Clemson University & Grad \\
\hline Mitch Goshert & Chemistry & University of Missouri & Grad \\
\hline Patrick Harms & Geology & $\begin{array}{c}\text { Cal State University, } \\
\text { East Bay }\end{array}$ & Grad \\
\hline Corey Keith & Nuclear Engineering & $\begin{array}{c}\text { Texas A\&M } \\
\text { University, College } \\
\text { Station }\end{array}$ & Grad \\
\hline Morgan Kelley & Radiochemistry & $\begin{array}{l}\text { Washington State } \\
\text { University }\end{array}$ & Grad \\
\hline Jeff Rolfes* & Radiochemistry & $\begin{array}{l}\text { University of Nevada, } \\
\text { Las Vegas }\end{array}$ & Grad \\
\hline Rodrigo Tapia** & $\begin{array}{l}\text { Mathematics and } \\
\text { Chemistry }\end{array}$ & University of Georgia & Undergrad \\
\hline
\end{tabular}

*= Nuclear Forensics Graduate Fellows

** = Nuclear Forensics Undergraduate Intern 
Table 2. Student Projects and Mentors

\begin{tabular}{|c|c|c|}
\hline Student & Mentor & Project \\
\hline Marisa Alfanso & Dawn Shaughnessy & $\begin{array}{c}\text { Analysis of Vanadium Activation Products from NIF } \\
\text { Irradiations }\end{array}$ \\
\hline $\begin{array}{l}\text { Lucas Boron- } \\
\text { Brenner }\end{array}$ & Gary Eppich & $\begin{array}{c}\text { U Isotopic Measurements of Fallout Spherules Using } \\
\text { Isotope Dilution Mass Spectrometry }\end{array}$ \\
\hline Megan Deeds & Natalia Zaitzev & $\begin{array}{l}\text { Fundamental Study of Scintillation Materials and their } \\
\text { PSD Properties }\end{array}$ \\
\hline Chad Durrant* & $\begin{array}{l}\text { James Begg/ } \\
\text { Mavrik Zavarin }\end{array}$ & $\begin{array}{c}\text { Environmental Transport of Pu: Desorption of Pu in a } \\
\text { Multi-Mineral System }\end{array}$ \\
\hline $\begin{array}{l}\text { Marc } \\
\text { Fitzgerald* }\end{array}$ & Kim Knight & Spatially Resolved Analyses of Historical Fallout \\
\hline April Gillens* & Mike Singleton & $\begin{array}{c}\text { Characterization of TBP using FTIR-ATR and Carbon } \\
\text { Stable Isotopes. }\end{array}$ \\
\hline Mitch Goshert & Patrick Huang & $\begin{array}{c}\text { Bonding and Redox Behavior in Actinide Coordination } \\
\text { Complexes: First Principles }\end{array}$ \\
\hline Patrick Harms & Brad Esser & $\begin{array}{l}\text { Tritium and Stable Isotope Survey of California Surface } \\
\text { Water }\end{array}$ \\
\hline Corey Keith & Brian Bandong & High Energy Neutron Foil Activation for Davis Cals \\
\hline Morgan Kelley & Jennifer Jo Ressler & Validation of a Phenomenological Fission Model. \\
\hline Jeff Rolfes* & Roger Henderson & Development of a Chemical System for Rutherfordium \\
\hline Rodrigo Tapia** & Brett Isselhardt & $\begin{array}{l}\text { Using Computed Tomography to Non-Destructively } \\
\text { Characterize Radioactive Fallout in 3D }\end{array}$ \\
\hline
\end{tabular}

$*=$ Nuclear Forensics Undergraduate Intern

$* *=$ Nuclear Forensics Graduate Fellows 
Table 3. Seminar Schedule

\begin{tabular}{|c|c|c|}
\hline Date & Speaker & Topic \\
\hline $6 / 20 / 13$ & $\begin{array}{c}\text { Dawn Shaughnessy } \\
\text { Group Leader, Experimental Nuclear and } \\
\text { Radiochemistry, Chemical Sciences Division }\end{array}$ & Superheavy Element Discovery at LLNL \\
\hline $6 / 27 / 13$ & \begin{tabular}{|c} 
Mona Dreicer \\
Deputy Program Director for Nuclear and Domestic \\
Security and Deputy Director of the Center for \\
Global Security Research (CGSR)
\end{tabular} & Treaty Monitoring and Verification \\
\hline $7 / 3 / 13$ & $\begin{array}{c}\text { Arthur Rodgers } \\
\text { Scientist, Earth and Energy Division }\end{array}$ & $\begin{array}{c}\text { Prompt Forensics with Speed-of-Sound } \\
\text { Data }\end{array}$ \\
\hline 7/11/13 & $\begin{array}{c}\text { Stephan Friedrich } \\
\text { Scientist, Physics Division }\end{array}$ & $\begin{array}{c}\text { Superconducting Gamma Spectrometers } \\
\text { with UItra-high Energy Resolution for } \\
\text { Nuclear Forensics }\end{array}$ \\
\hline $7 / 18 / 13$ & $\begin{array}{c}\text { James Begg, Postdoc, Chemical Sciences Division } \\
\text { Greg Brennecka, Postdoc, Chemical Sciences } \\
\text { Division }\end{array}$ & $\begin{array}{l}\text { Actinides in the Environment } \\
\text { Geolocation of Nuclear Materials for } \\
\text { Forensic Applications }\end{array}$ \\
\hline $7 / 25 / 13$ & $\begin{array}{c}\text { Brett Isselhardt, } \\
\text { Scientist, Chemical Sciences Division }\end{array}$ & Case Studies in Nuclear Forensics \\
\hline $8 / 1 / 13$ & $\begin{array}{l}\text { Kim Budil } \\
\text { N Program Manager, Nuclear Counterterrorism, } \\
\text { Global Security Principal Directorate }\end{array}$ & $\begin{array}{c}\text { A Journey Through the Nuclear Core: A } \\
\text { Career at LLNL }\end{array}$ \\
\hline 8/8/13 & $\begin{array}{c}\text { Annie Kersting } \\
\text { Director, Glenn T. Seaborg Institute, Physical and } \\
\text { Life Sciences Directorate }\end{array}$ & Closing out the program \\
\hline
\end{tabular}




\section{Analysis of Vanadium Activation Products from NIF Irradiations}

Marisa Alfonso ${ }^{1,2}$, Evgeny Tereshatov ${ }^{1}$, John Despotopulos ${ }^{1,3}$, Narek Gharibyan ${ }^{1}$, Ken Moody ${ }^{1}$, Dawn Shaughnessy

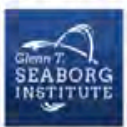

${ }^{1}$ Lawrence Livermore National Laboratory, Chemical Sciences Division, PLS

${ }^{2}$ Texas A\&M University ${ }^{3}$ University of Nevada - Las Vegas
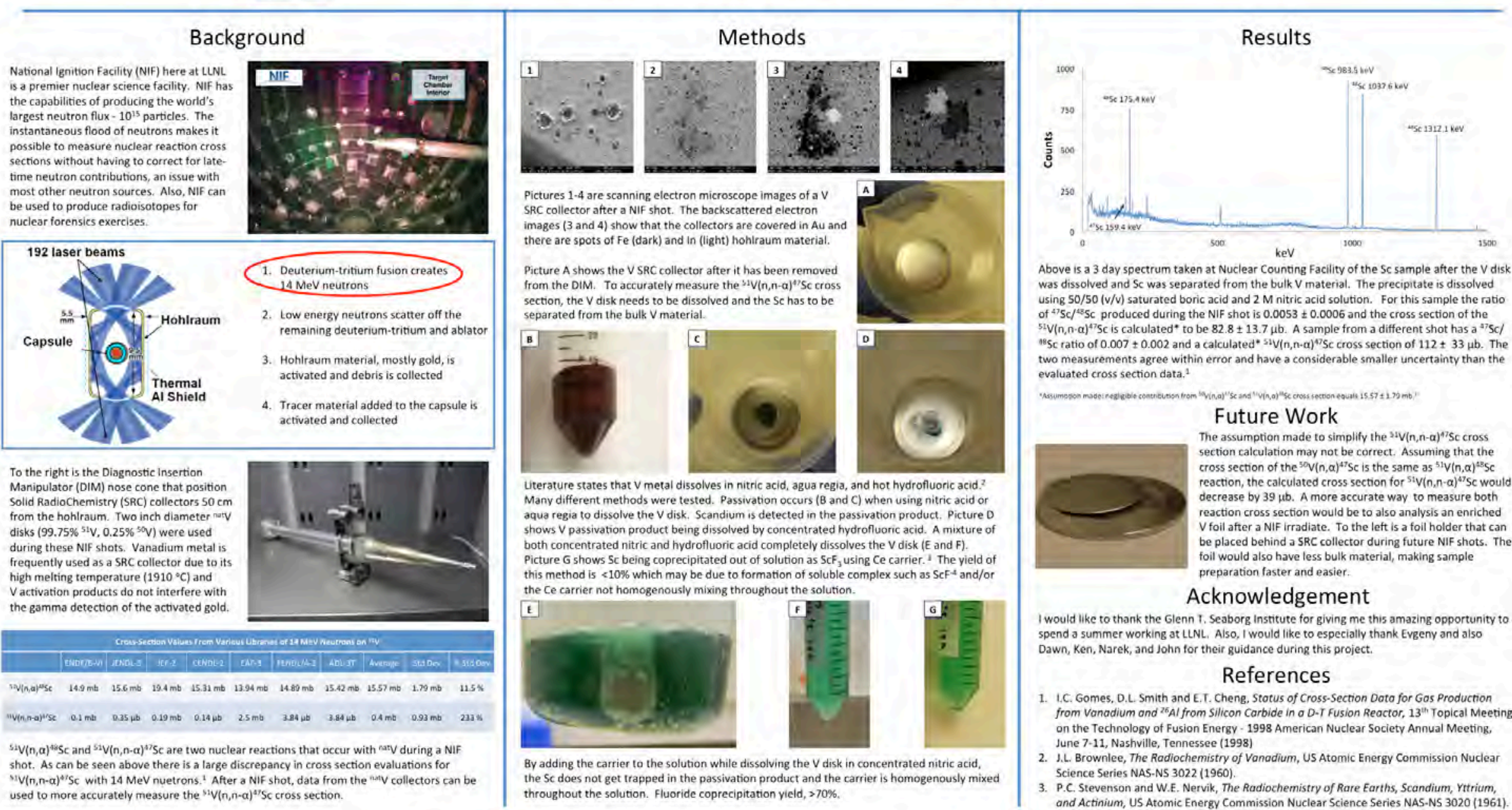

Above is a 3 day spectrum token at Nuclear Counting Facility of the Sc sample after the $V$ disk was dissolved and $\mathrm{Sc}$ was separated from the bulk $\mathrm{V}$ material. The precipitate is dissolved using 50/50 (v/v) saturated boric acid and $2 \mathrm{M}$ nitric acid solution. For this sample the ratio of 4 Sc/ $/$ - $5 \mathrm{Sc}$ produced during the NIF shot is $0.0053 \pm 0.0006$ and the cross section of the

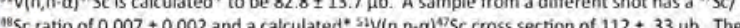

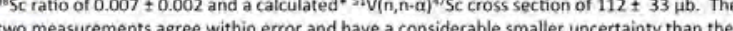
evaluated cross section data. ${ }^{1}$

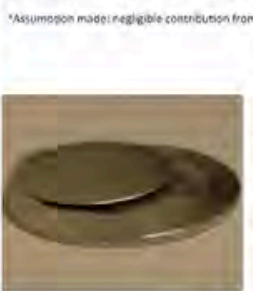

Future Work

The assumption made to simplify the ${ }^{3+V(n, n-1-a)^{n}}$ isc cross coss section of the may not be correc. Assuming that the

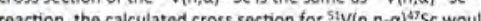
decrease by $39 \mu \mathrm{b}$. A more accurate way to measure both reaction cross section would be to also analysis an enriched $V$ foil after a NIF irradiate. To the left is a foil holder that can be placed behind a SRC collector during future Nif shots. The poil would also have less bulk mastion faster and easier.

Acknowledgement

I would like to thank the Glenn 1. Seaborg instute for giving me this amazing opportunity to spend a summer working at LLNL. Also, I would like to especially thank Evgeny and also

Dawn, Ken, Narek, and John for their guidance during this project.

\section{References}

L.C. Gomes. D.L. Smith and E.T. Cheng, Stotus of Cross-Section Doto for Gas Production

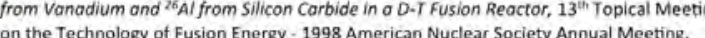
June 7-11, Nashville, Tennessee (1998) J.L. Brownlee, The Radiochemistry of Vanadium, US Atomic Energy Commission Nucle Science Series NAS-NS 3022 (1960)

P.C. Stevenson and W.E. Nervik, The Radiochemistry of Rare Earths, Scandium, Ytrium, 


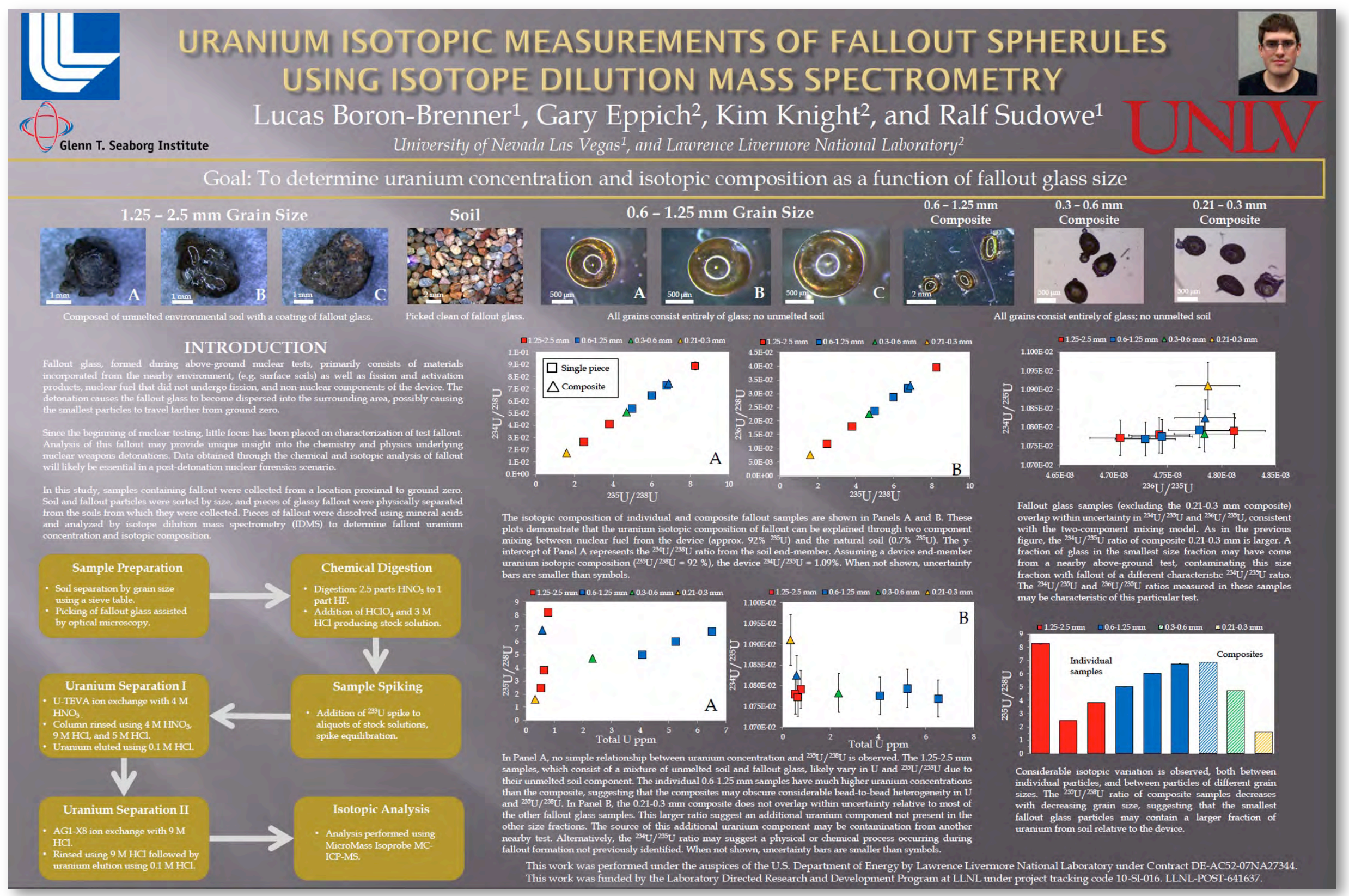




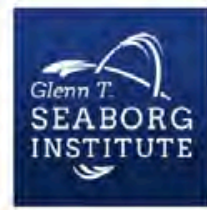

\section{Fundamental Study of Scintillating Materials and their PSD Properties}

Megan E. Deeds, H. Paul Martinez, Natalia Zaitseva*, Leslie Carman, Andrew Glenn, and Mareena Robinson Lawrence Livermore National Lab, 7000 East Ave. Livermore, CA 94550
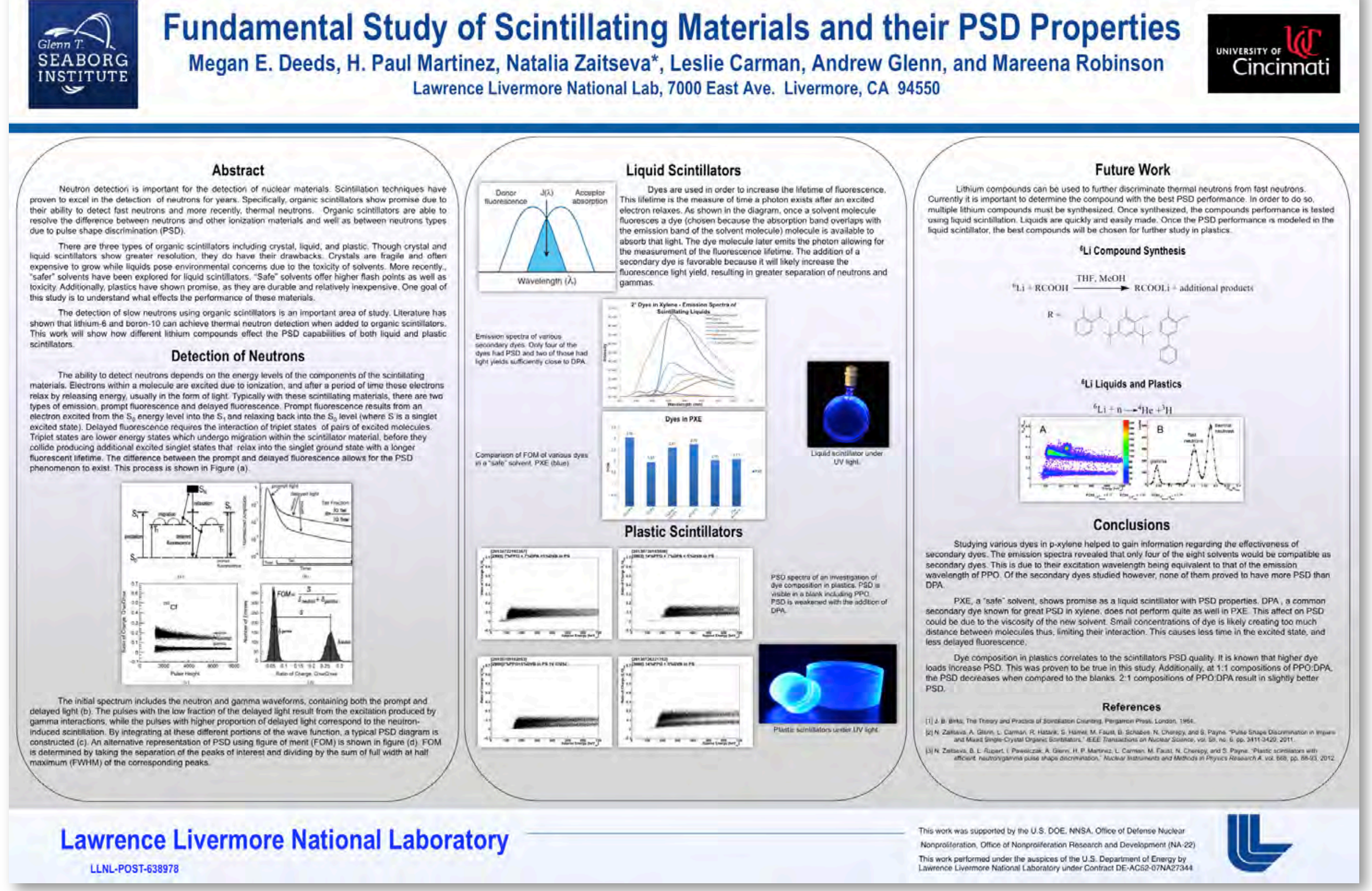


\section{ENVIRONMENTAL TRANSPORT OF PU: DESORPTION OF PU(IV) IN A MULTI-MINERAL SYSTEM}

Chad Durrant ${ }^{1,2}$, James Begg', Mavrik Zavarin', Pihong Zhao', Annie B. Kersting' Glenn T. Seaborg Institute, 2 Penn State University
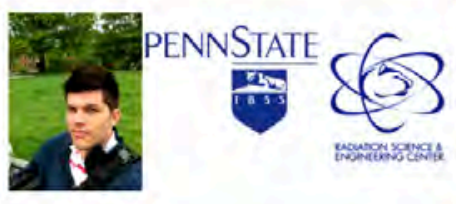

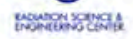

\section{- Plutonium Transport}

- Globally 2000 MT Pu released to the environment [1]

- Understanding subsurface Pu transport is of vital importance.

- Mineral colloids identified as an important transport vehicle for Pu.

Study Pu-mineral colloid interactions to develop transport models.

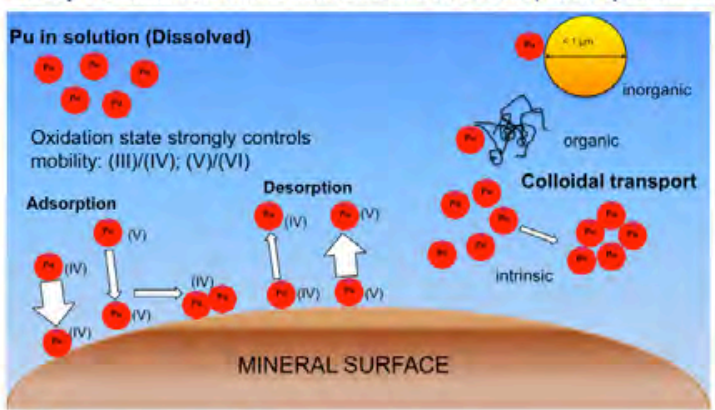

\section{Project Goals}

Understanding the behavior of plutonium in complex mineral systems. Specifically, how will adding a second mineral affect the stability of plutonium that is aged onto a first mineral.

$\begin{array}{ll}\text { 2Experimental Set-up } & \text { Studies conducted at } \mathrm{pH} 4 \\ \text { and } \mathrm{pH} 8\end{array}$

\section{- Troubleshooting}

Initially no plutonium was seen diffusing through the Float-A-Lyzer membrane. To determine the cause of this phenomena two initial possibilities were raised:

- Perhaps the high concentration of montmorillonite was causing interference during liquid scintillation counting

- Perhaps the pore size was not large enough for Pu to diffuse through

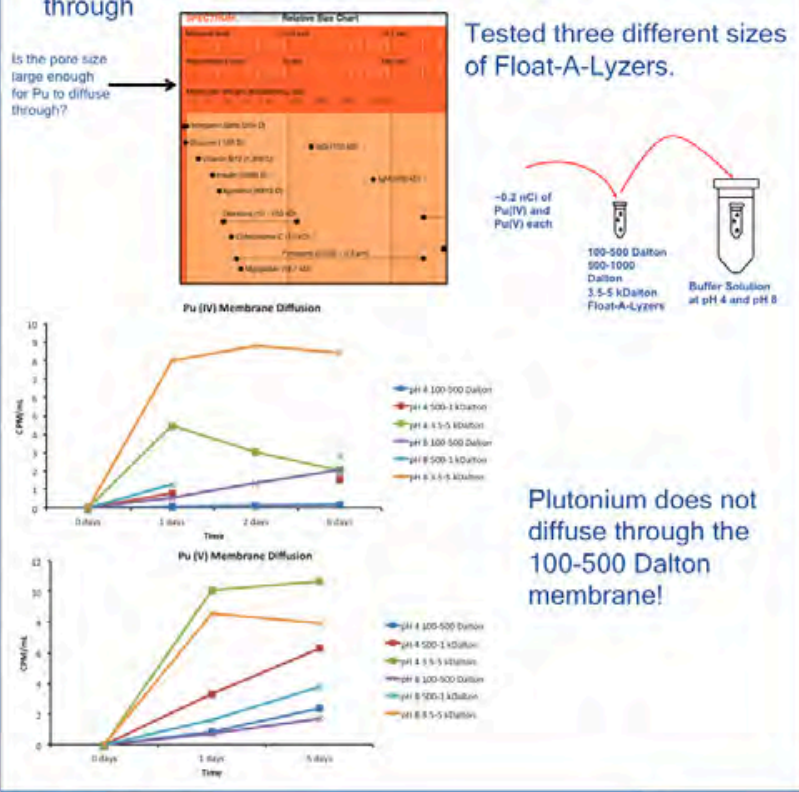

\section{Acknowledgements}

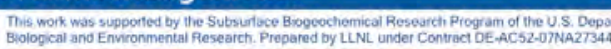

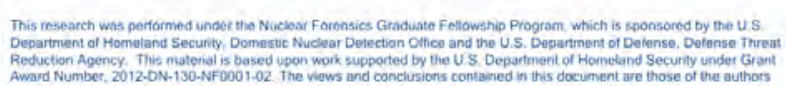

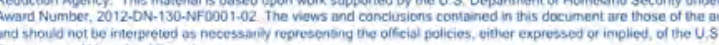

\section{(4) Results}

After determining that a larger pore size Float-ALyzer was needed the flotation cells were set up again with the remaining goethite and bentonite aged $\mathrm{Pu}(\mathrm{IV})$ solutions.

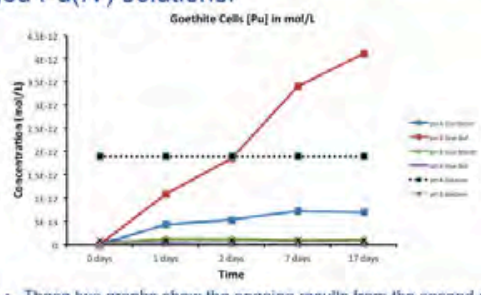

- These two graphis stiow the ongoing results from the second set of desorption experiments.
The concentrations represent the amount of plutonium in the - The concentrations represent the amount of plutonium in the
bulk phase of the flotation coll - The concentration of a $1: 1$ dilution of the initially free plutonium - It appears that the addition of a second mineral is increasing the
desorption of plutonium from the first mineral in the bentonite

Dells.

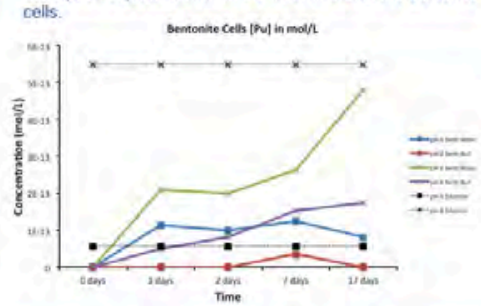

\section{- Moving Forwards}

Testing the selective affinity for adsorption of plutonium in multiple mineral systems.

Adding organic material to the flotation systems to see the effects on desorption. 


\section{|| Developing Spatially Resolved Analyses of Historical Fallout \\ Fitzgerald, Marc ${ }^{1}$; Knight, Kim²; Stone, Gary²; Calderia, Lee²; Austin, Kevin²; Ramon, Erick²; Czerwinski, Ken ${ }^{1}$; Hutcheon, Ian²}

1. University of Nevada Las Vegas

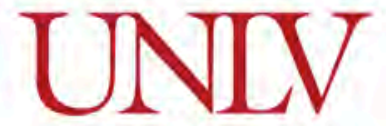

Pile

Glenn T. Seaborg Institute

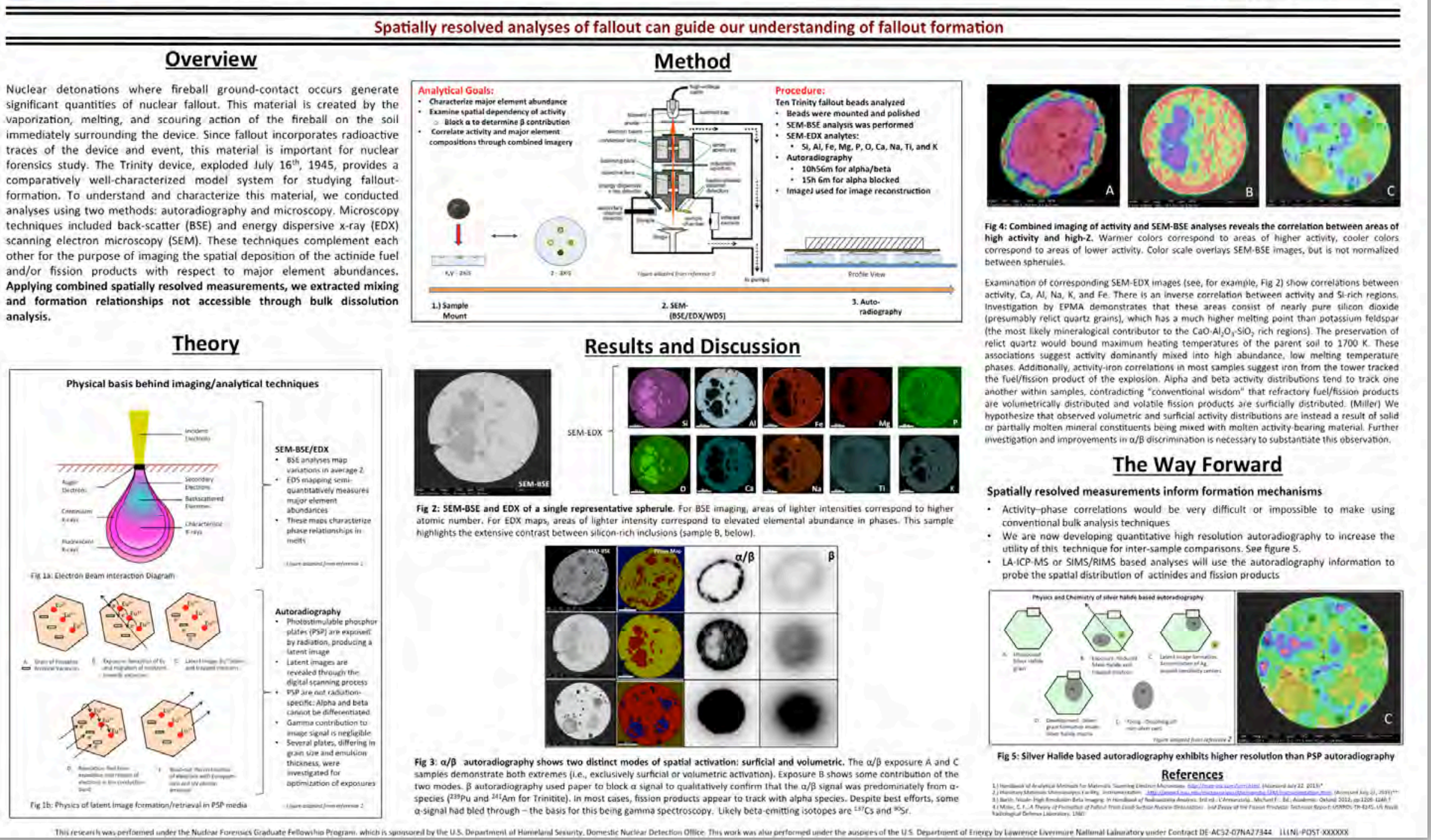

LLNL-POST-760588 


\section{CLEMSON Characterization of TBP using FTIR-ATR and Carbon Stable Isotopes}

April R. Gillens ${ }^{1}$, Michael Singleton ${ }^{2}$, and Brian A. Powell ${ }^{1}$; ${ }^{1}$ Environmental Engineering and Earth Sciences, Clemson University, Clemson, SC ${ }^{2}$ Environmental Radiochemistry Group, Chemical Sciences Division, Physical and Life Sciences Directorate, Lawrence Livermore National Laboratory, Livermore, CA

\section{Research Objectives}

The objective of this research is to determine the carbon stable isotope signatures of tributyl phosphate (TBP) and its degradation products after contact with nitric acid and sodium hydroxide for the purpose of identifying if there is a unique carbon isotope signature in nuclear reprocessing and solvent disposal. The degradation products considered in this research are limited to dibutyl phosphate (DBP) and butanol. In order to meet this objective, studies will be conducted involving the following instrumentation:

- Fourier Transform Infrared Spectroscopy with Attenuated Total Reflectance (FTIR-ATR)

- Gas chromatography Flame Ionization Detection (GC-FID)

- Gas Chromatography Combustion Isotope Ratio Mass Spectrometry (GC-C-IRMS)

TBP Degradation Mechanisms

Acidic Hydrolysis vs.

Basic Hydrolysis

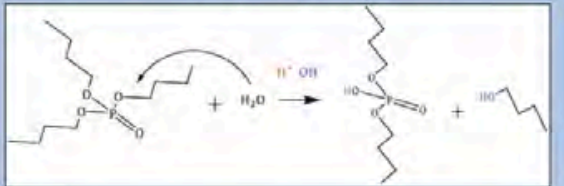

$\left(\mathrm{C}_{4} \mathrm{H}_{9} \mathrm{O}\right)_{3} \mathrm{PO}+\mathrm{H}_{2} \mathrm{O} \stackrel{\mathrm{H}^{+}+\mathrm{OH}^{-}}{\longrightarrow}\left(\mathrm{C}_{4} \mathrm{H}_{9} \mathrm{O}\right)_{2} \mathrm{PO}(\mathrm{OH})+\mathrm{C}_{4} \mathrm{H}_{9} \mathrm{OH}$

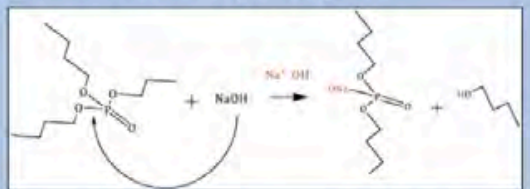

$\left.\mathrm{NaOH}+\mathrm{CH}_{3}-\mathrm{CH}_{2}-\mathrm{CH}_{2}-\mathrm{CH}_{2}-\mathrm{O} \cdots \mathrm{PO}_{(\mathrm{OC}} \mathrm{H}_{9}\right)_{2}$
FTIR-ATR Peak Intensity Ratio Technique Acidic Hydrolysis

vs.

Basic Hydrolysis
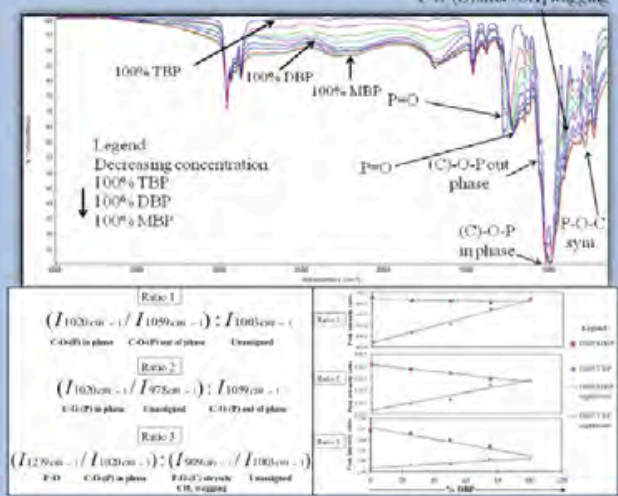

FTIR-ATR Results
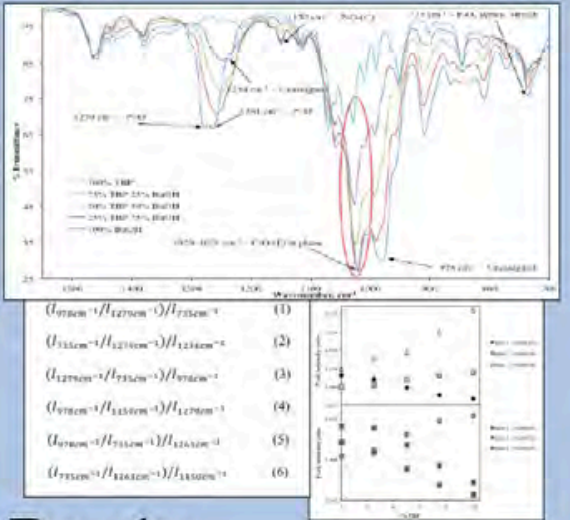

A. A. A sample of TBP degraded in $8 \mathrm{M} \mathrm{HNO}_{3}$
was evaluated using the peak intensity ratios Carbon isotope analysis should confirm the degradation mechanisms of TBP in acidic and above. The linear regression developed for a TBP/DBP system alkaline conditions. A carbon isotope fractionation is not expected for TBP in alkaline conditions saturated in $8 \mathrm{M} \mathrm{HNO}_{3}$ was used. Ratios 1 and 2 are more because the $\mathrm{P}-\mathrm{O}$ bond would repture keeping the carbon in the molecule intact. A carbon reliable and te results of ratio 3 do not reflect the conditions of isotope fractionation is expected for $\mathrm{BBP}$ in acidic conditions because of the cleavage of the C - the sample. After five weeks of hydrolysis, an average of $68 \%$ of $\mathrm{O}$ bond associated with TBP degradalion under this condition. Hence, this work will deternine DBP is produced according to ratios 1 and 2 . These results have whether there is a unique carbon isotope signature for TBP in nuclear reprocessing and disposal not be verified by gas chromatography. B. This figure describes by studying the fandament che reaction the average amounts of TBP remaining and butanol formed mechanisms for TBP degadatis is aciated uncertainties for a TBP alkal mechanisms proceed differently, the same degradation products are generated in addition to hydrolysis experiment invol other produch technique using phases while most of the degradation products from alkaline hydrolysis are found in the aqueous saturated and unsaturated phases while most of the degradation products from alkaline hydrolysis are found in the aqueous
phase. The difference in how TBP degrades in acidic and alkaline media could have major implications on the "signature" of the molecule as a result of its use in nuclear reprocessing and gas chromatography. solvent disposal.

\section{Acknowledgements}

References

This material is based upon work supported by the U.S. Department of Homeland Security under Grant Award Number, 2012-DN-130-NF0001-02. The views and conclusions contained in this document are those of the authors and should not be interpreted as necessarily representing the official policies, either

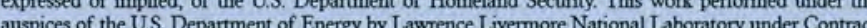
DE.AC52.07NA27344.
Carbon stable isotope signatures of TBP

The GC.C-IRMS system consists of an A pilent 6890 gas chromatograph coupled with a combustion furnace, which leads to an IsoPrime is equipped with a 30 meter by 0.25 millimeter (inver diamerter) HP-5MS ( $5 \%$ Phenyl Methyl Siloxane) Ultra Inert fused silica capillary column with $0.25 \mu \mathrm{m}$ film thickness. Samples are introduced using a splitless/purge injection port set at $250^{\circ} \mathrm{C}$. The GC oven is heated using the following program: isothermal for 1 minute at $50^{\circ} \mathrm{C}, 8^{\circ} \mathrm{C} / \min$ to $100^{\circ} \mathrm{C}, 16^{\circ} \mathrm{C} / \min$ to $230^{\circ} \mathrm{C}, 100^{\circ} \mathrm{C} / \min$ to $300^{\circ} \mathrm{C}$, and isothermal for 2 minutes for a runtime of 18.08

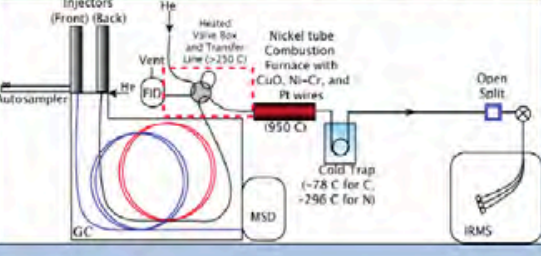
constant flow rate of $0.8 \mathrm{~mL} / \mathrm{min}$ and average velocity of $32 \mathrm{~cm} / \mathrm{sec}$. 

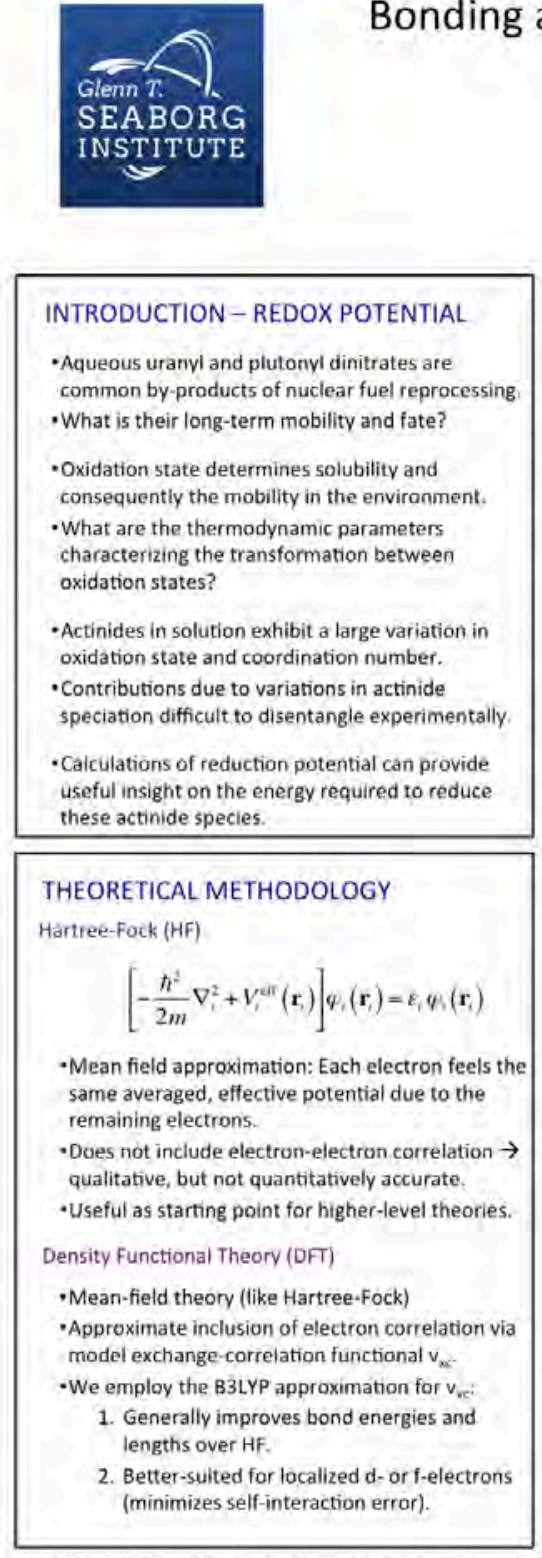

Bonding and Redox Behavior in Actinide Coordination Complexes: A First Principle Study

Mitchell Gashert, ${ }^{1}$ Patrick Huang, ${ }^{2}$ and Justin Walensky ${ }^{2}$

Physical and Life Sciences Directorate and Glenn T. Seaborg Institute

${ }^{i}$ University of Missouri, Columbia

2Lawrence Livermore National Laboratory

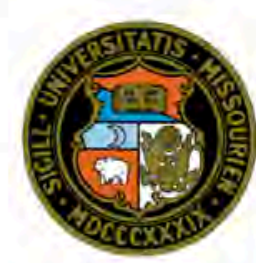

\section{SOLVENT MODEL \\ Conductor flike Polarizable Continuum Model (CPCM) \\ STRUCTURES \\ U $\mathrm{N}^{\mathrm{N}} \mathrm{O}_{2}\left(\mathrm{NO}_{3}\right)_{2}\left(\mathrm{H}_{2} \mathrm{O}\right)_{2}$ - Bond Lengths}

-Solvent effects are an important influence on

reduction potentials.

- Model solvent as a continuum dielectric.

-Need to assume a conductor-like cavity containing

solute.

-CPCM well.established for polar solvents (e.g., water).

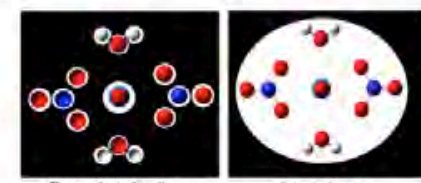

For labre a unsphericical complexes, shape-adapted cavities are necessary.

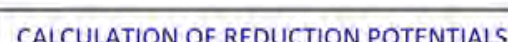
-Free energies are calculated relative to a standard hydrogen electrode

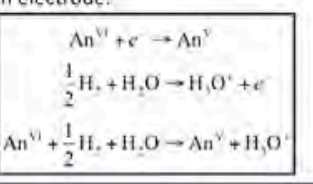

OPTIMIZATION OF BOTH U(VI) AND U(V) SPECIES

-The structures of the $\mathrm{UO}_{3}\left(\mathrm{NO}_{3}\right)_{2}\left(\mathrm{H}_{2} \mathrm{O}\right)_{2}$ complex in both $U(V)$ and $U(V)$ oxidation states were optimized.

-Vibrational analysis was employed to verify the stability of optimized structures.

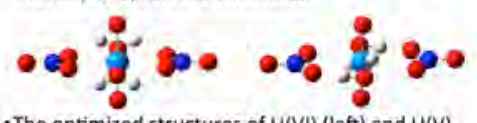

The optimized structures of U(VI) (left) and U(V) (right).

\begin{tabular}{|c|c|c|c|c|c|}
\hline & HF (gas) & HF (solv) & B3LYP Igas & ) B3LYP /solv) & Expt \\
\hline & 1.71 & 1.71 & 1.77 & 1.77 & 1.76 \\
\hline$u-O_{t \rightarrow 0}|\bar{A}|$ & 2.56 & 2.53 & 2.55 & 2.52 & 2.45 \\
\hline $1-O_{N o 3}[A]$ & 250 & 2.53 & 2.49 & 2.50 & 2.48 \\
\hline
\end{tabular}

1. Errors in $\mathrm{H}_{2}$ half-reaction
- B3LYP shows an improved $\mathrm{U}=O$ bond length over $\mathrm{HF}$ to within $\sim 0.01 \mathrm{~A}$ -Both $\mathrm{HF}$ and $\mathrm{B} 3 \mathrm{~L} . \mathrm{YP}$ yield significant lengthening of both $\mathrm{U}-\mathrm{O}_{H z 0}$ bonds relative to experiment

- Both HF and B3LYP accurately predict the $\mathrm{U}-\mathrm{O}_{\mathrm{NO}}$ bond length within

洪

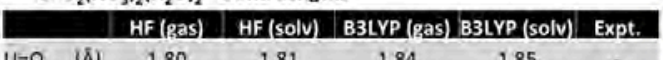

$\begin{array}{llllll}\mathrm{U}=0 & {[\AA]} & 1.80 & 1.81 & 1.84 & 1.85\end{array}$ $\begin{array}{lllll}U-O_{\text {H20 }}[\AA \AA] & 273 & 2.63 & 2.71 & 2.62 \\ U-O_{\text {No3 }}[A] & 2.67 & 2.63 & 2.61 & 2.61\end{array}$

- Uranyl $V$ bond lengths show 01 A increase on average over uranyl VI.

\section{REDUCTION POTENTIALS}

\begin{tabular}{|c|c|c|c|c|}
\hline & & & pas I & \\
\hline$U(V I)+e \rightarrow U(V)$ & 212 & 4.22 & 2.86 & 4.60 \\
\hline & 8.02 & 4.67 & 8.96 & \\
\hline & -5.90 & -0.45 & -6.10 & $-1: 1$ \\
\hline
\end{tabular}

$\begin{array}{lrrrr}\text { Reduction Putentials } & -5.90 & -0.45 & -6.10 & -1.78\end{array}$

- Inclusion of solvation effects yields a $\sim 4.9 \mathrm{eV}$ improvement over the gas phase model.

- Discrepancy between $\mathrm{E}^{0}$ (solv) and expt. likely due to:

2. Lack of explicit second coordination sphere.

Errors for calculated actinide reduction potential typically $-2-3 \mathrm{eV}$

[Hay, L. P; Martin, R. L. Li. Schreckenbach, G.L. Phys, Chem. A 2000, 104]

- Experimental data for the reduction potential of $\mathrm{UO}_{2}\left(\mathrm{H}_{2} \mathrm{O}\right)_{5}$ is $0,16 \mathrm{eV}$. meaning our data is reasonable

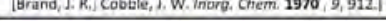

\section{CONCLUSIONS - REDOX POTENTIALS}

- Benchmark studies have been done on $\mathrm{UO}_{2}\left(\mathrm{NO}_{3}\right)_{2}\left(\mathrm{H}_{2} \mathrm{O}\right)_{2} \mathrm{VI}$ and $\mathrm{V}$

- Our model involves an explicit representation of the first coordination sphere plus a continuum dielectric for the solvent environment.

- Solvation effects are essential for description of red, potentials.
INTRODUCTION - BONDING BEHAVIOR

- Uranium trioxide, $\mathrm{UO}_{j,}$ is the major precursor used for nuclear energy throughout the world.

- However, due to its poor solubility in organic solvents, little chemical information is known about $\mathrm{UO}_{3}$.

- Examining the structure, bonding, and reactivity of analogs will provide insight into $\mathrm{UO}_{3}$ chemistry. - The Bart group at Purdue University has synthesized two tris(imido)uranium complexes which are

isoelectronic with $\mathrm{UO}_{3}$.
- $A$ i initio methods were used to calculate the ground state structure of the synthesized compounds.

STRUCTURES - GEOMETRY OPTIMIZATION - Geometry optimizations were performed on both the $\mathrm{U}(\mathrm{PDI})(\mathrm{NDIPP})_{3}$ (left) and $\mathrm{U}(\mathrm{PDII})(\mathrm{NMes})_{3}$ (right)

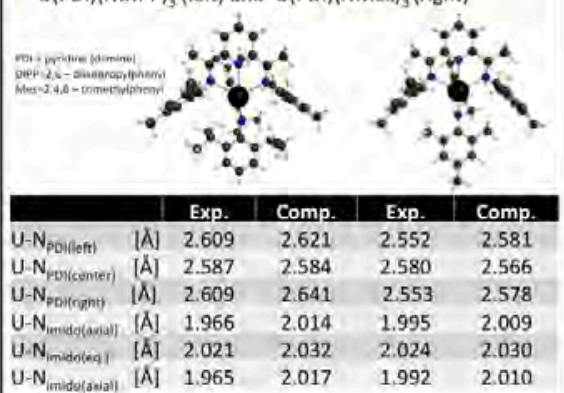

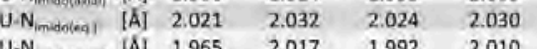

\section{CONCLUSIONS - BONDING BEHAVIOR}

- A successful geometry optimization has been completed

- A successlur geometry optimization has been completed $\sim 0.05 \AA$ accuracy

- The U(PDI)(NMes), optimization has not fully converged but demonstrates an accuracy within $\sim 0.03 \mathrm{~A}$

\section{ACKNOWLEDGEMENTS}

-M.G. gratefully thanks the Glenn T. Seaborg Institute and Laboratory Directed Research and Development for their
financial support. 


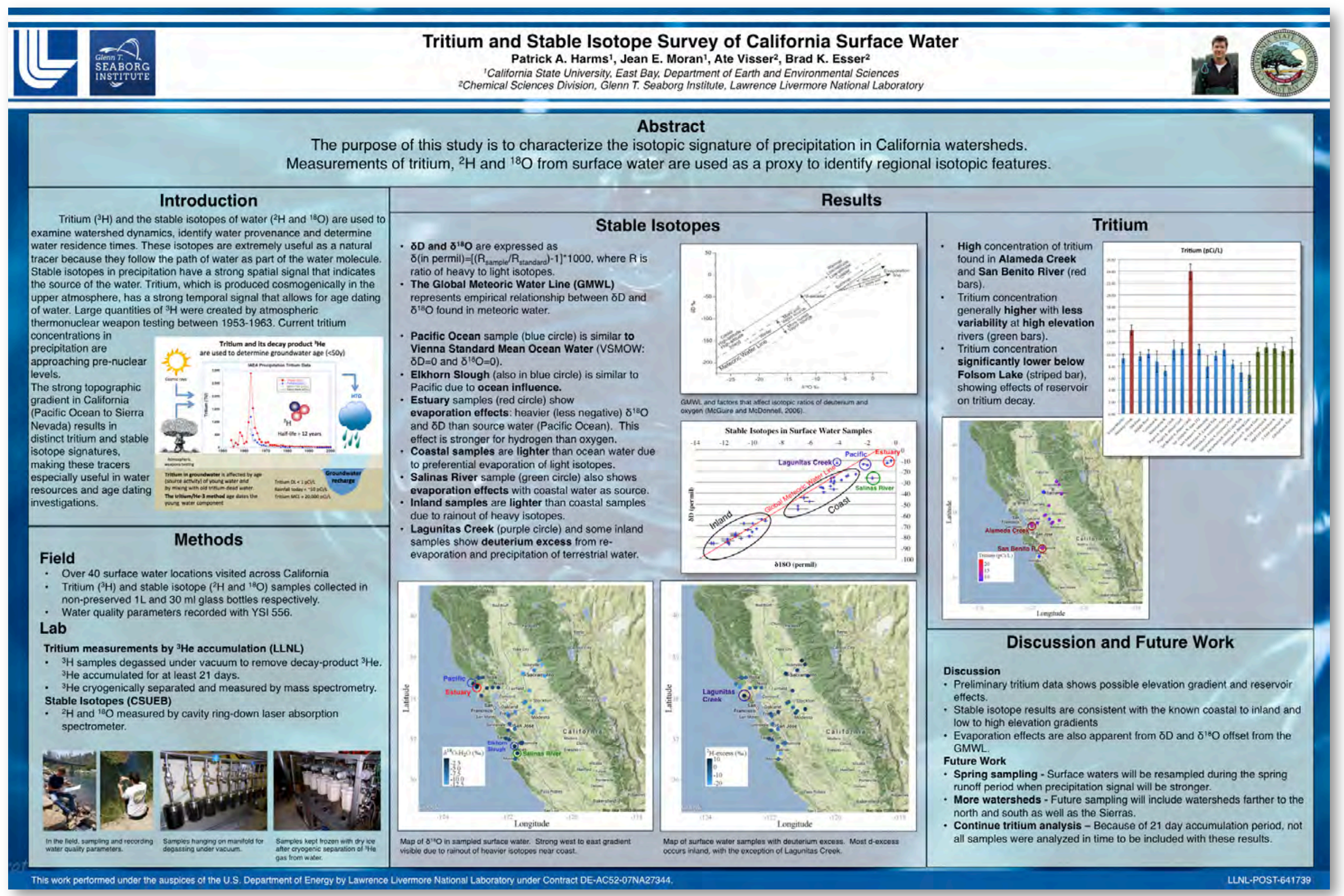




\section{High-Energy Neutron Foil Activation for Davis Cals}

\section{Corey Keith ${ }^{1}$, Bryan Bandong², Robert Haslett ${ }^{2}$, Kip Harward ${ }^{2}$, Tzu Wang ${ }^{2}$, Kevin Roberts ${ }^{2}$}

${ }^{1}$ Texas A\&M University, Department of Nuclear Engineering, College Station, TX

${ }^{2}$ Lawrence Livermore National Laboratory, Physical and Life Sciences, Chemical Sciences Division, Livermore CA

Davis Cals are inter-laboratory measurements and calibration comparisons of "threshold detector products". High-energy neutron foil activation is used for the isotope production, and the goal is to model this process and compare to experimental results.

\section{Introduction}

Radioanalytical measurements on activation species are being performed by LLNL, LANL, and PNNL. The activation species used for the inter-laboratory measurements are produced at the 76-inch Cyclotron at UC Davis Crocker Nuclear Laboratory by irradiating various detector metal foils with high-energy neutrons produced from bombarding a thick beryllium target with $40 \mathrm{MeV}$ deuterons. The existing nuclear data for $(\mathrm{d}, \mathrm{n})$ reactions for beryllium, as well as production cross sections for the foils, are very limited in the evaluated energy ranges of the fast neutron spectrum. As a result, it was proposed to use physics models and Monte Carlo codes to simulate isotope production and compare with recent experimental results.

\section{Neutron Flux Profile on Au Foil}

To evaluate the differences between physics models and beam width on isotope production, the neutron flux profile on Au foil was evaluated.
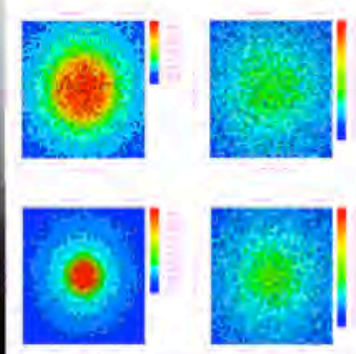

Top Lef: INCLA os $\mathrm{cm}$ beam widh; Bottom Left: INCLA $025 \mathrm{~cm}$ crm beam width: Bottom Right:

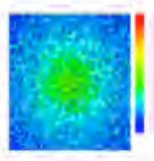

\section{Setup}

Various physics models that use both intranuclear cascade (INC) and evaporation physics were used to model $(\mathrm{d}, \mathrm{n})$ reactions. Early results showed that, for $40-\mathrm{MeV}$ deuterons, changes in evaporation models had little impact, and so differences between three INC models (CEM03' ${ }^{1}$, Bertini ${ }^{2}$ and INCL4 ${ }^{3}$ ) were evaluated. MCNPX 2.7 was used to evaluate neutron transport in the system and reaction rates in the foils.
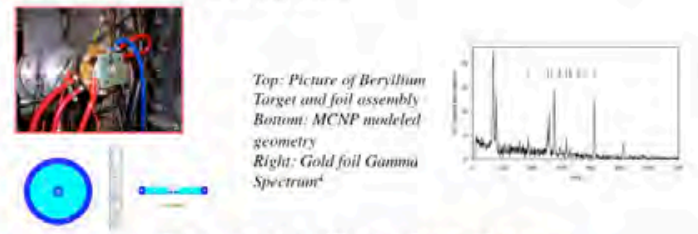

\section{Isotope Production}

Isotope Production for the gold and titanium foils were evaluated using MCNPX and the ENDF and TENDL cross sections. The activation run was conducted on $12 / 27 / 2012$

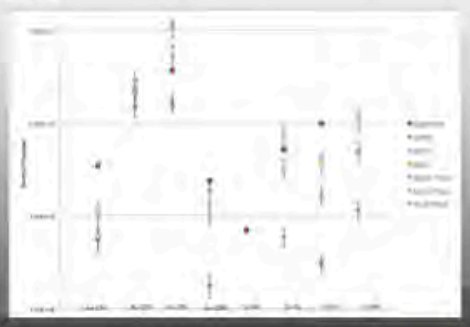

\section{Neutron Flux}

Neutron Flux for various INC physics models evaluated for a for a $6.0 \pm 1,7 \mu \mathrm{A}$ beam current.

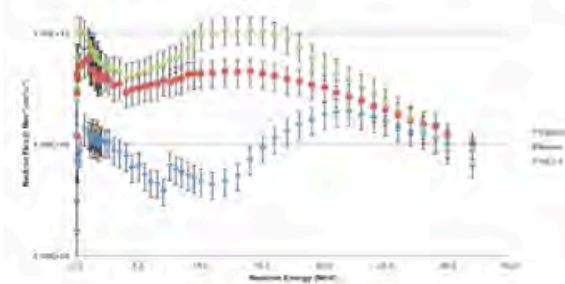

\section{Discussion}

The three INC models all have limits of reliability in the energy range being explored when compared with recent experimental data. The TENDL cross sections for higher energy are in good agreement for the ${ }^{195} \mathrm{Au},{ }^{196} \mathrm{Au},{ }^{46} \mathrm{Sc}$. ${ }^{48} \mathrm{Sc}$ residual cross sections. Further work is needed to asses production pathways and cross sections for ${ }^{44} \mathrm{Sc}$. ${ }^{47} \mathrm{Se}$, and ${ }^{194} \mathrm{Au}$

\section{References:}

1. S.G. Mashnik, et al.. LANL Report LA-UR-05-7321, Los Alamos 2005, RSICC Code Package PSR-532.

2. H.W. Bertimi Phys. Rev., 131 (1063), p. 1801 3. A. Boudard at al. Phys. Rev, C. 66,20022, p. 04 is 4. I. I. Wilkens. Activation of 


\section{Validation of a Phenomenological Fission Model WASHINGTON STATE \\ Morgan Kelley ${ }^{1}$, Walid Younes ${ }^{2}$, Jennifer Jo Ressler ${ }^{2}$ \\ SUNIVERSITY}

1 Washington State University, Department of Chemistry, Pullman, WA

${ }^{2}$ Lawrence Livermore National Laboratory, Physical and Life Sciences, Nuclear Physics Division, Livermore CA

Fission data are very useful for both forensic and basic science applications. Unfortunately, these data often cannot be easily measured experimentally. Therefore, fission models/theories play an important role to fill in the gaps left by experiment. We will determine the extent to which the fission model GEF can be trusted.

\section{GEF: GEneral Fission model}

GEF' uses Monte Carlo methods used to

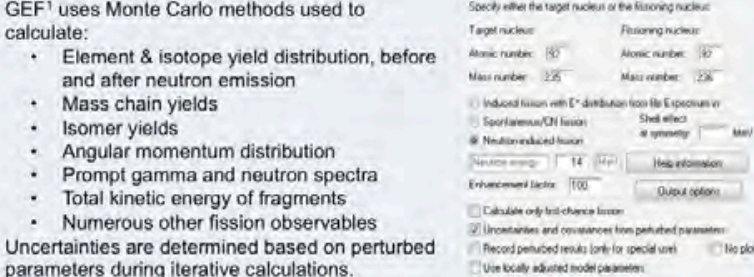

\section{First Assessment: GEF vs. Experiment}

Due to larger experimental uncertainties, the Pu239 Thermal data and GEF data match fairly well, while the U235 Thermal data from experiment is often outside of the GEF values

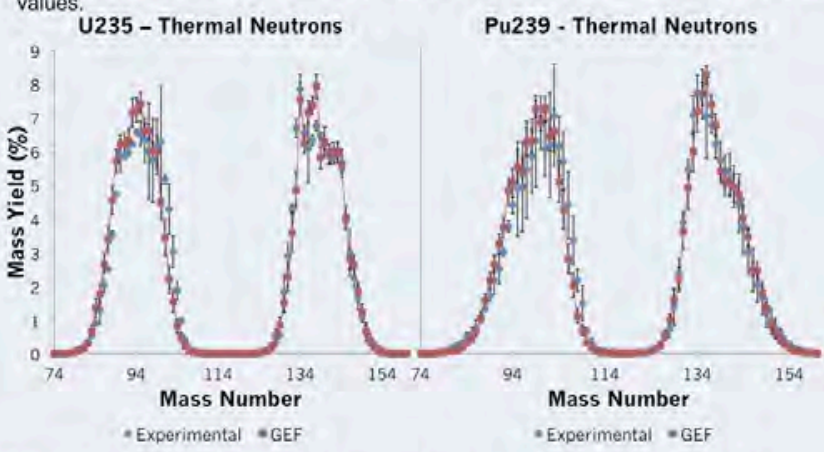

To treat the data in a more rigorous way $x^{2}$ for each fission product mass was calculated for various nuclides, and compared to the asymmetry:

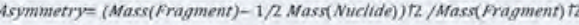

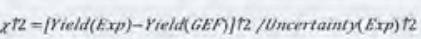

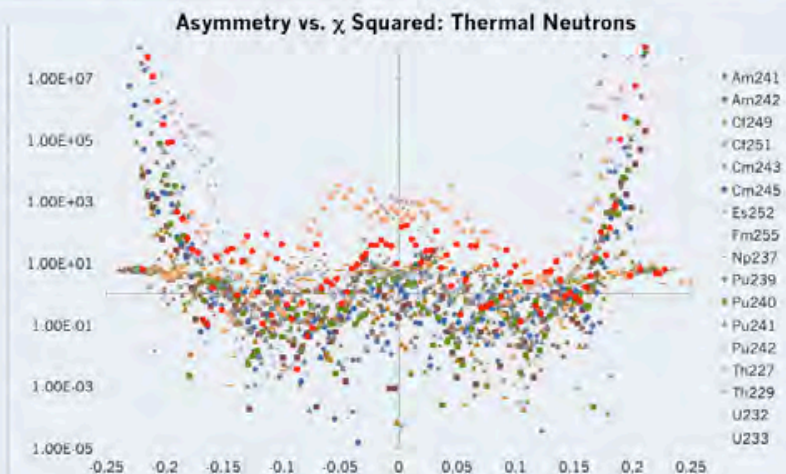

A single $x^{2}$ value was then calculated for each nuclide and compared to the $95 \%$ critical value testing if an obvious reason to reject the model existed. For low-yield masses, GEF's calculated yields are eclipsed by their uncertinties To exclude these values from the $x^{2}$ calculation, a yield threshold was set and systematically tested. These $x^{2}$ values were calculated taking correlation into account:

\section{$X T 2=\Delta Y T T \times V T-1 \times \Delta$}

$\Delta r$ is a vector containing the difference between experimental and GEF yields for each mass, and $v$ is the covariance matrix of the calculated GEF yields.

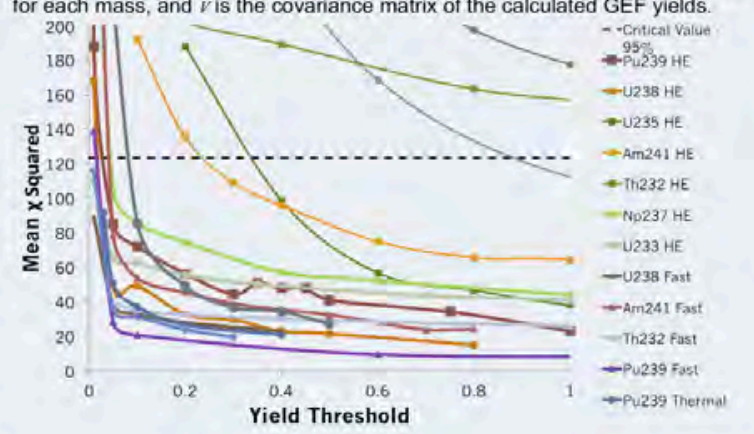

Mass-Chain Yields

In most cases, GEF does an acceptable job of reproducing experimental yields.

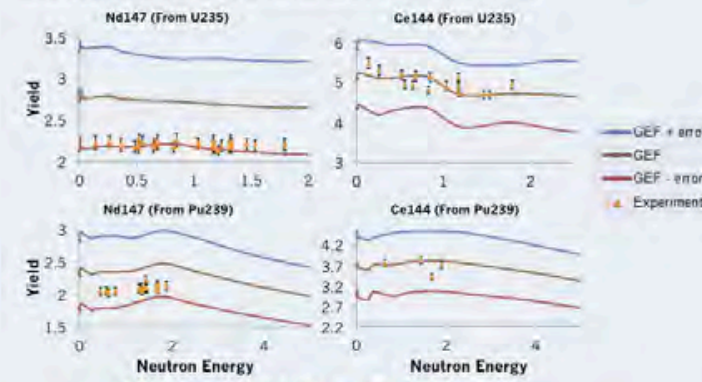

\section{Uncertainty Analysis}

$x^{2}$ values for most nuclides are well below the $95 \%$ confidence limit (GEF may be overestimating uncertainties). Edited the GEF code to include an error factor: a factor by which the internal GEF parameters - the parameters perturbed to generate the calculated uncertainty - are multiplied by. Investigated the effects of varying the error factor. Attempted to decrease the uncertainty without causing $x^{2}$ to increase to the $95 \%$ critical value. In a EFF can be reduced. 200
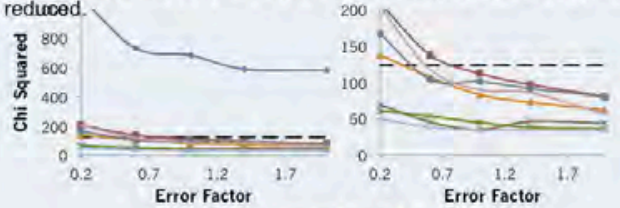

Conclusions

For many nuclides, GEF does an acceptable job of reproducing experimente values within experi

GEF gives a good starting point for an estimate of experimental yields. However, the type of validation presented here is critical to properly use these estimates and their respective uncertainties.

A 


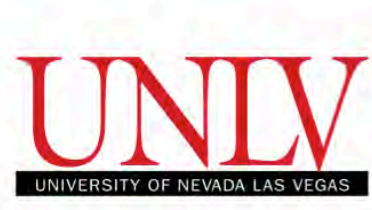

\section{Background}

Studies of the chemical properties of the heaviest elements have always been difficult due to the short hal elements have always been difficult due to the shor
lives and low cross sections involved. To solve this problem, atom-at-a-time methods are used to determine the properties of short-lived isotopes. Extremely fast. kinetics for the chemical reactions studied (on the same order as the nuclide's half-life) are required and the system should have potential for automation. One potential technique, extraction chromatography, offers a
way of investigating rutherfordium's properties, without the solvent waste generated in liquid-liquid extractions. A fast systematic method involving the use of a ligand with higher inner group selectivity is necessary to discover more about element 104. Using the homologs, zirconium and hafnium, studies can be performed using liquid-liquid extractions and extraction chromatography. From literature reviews, thiacrown ethers, tertiary amines, and calixarenes show promise in extracting group 4 elements. The development of an extraction

\section{Purpose}

While the primary goal of research involving rutherfordium and its homologs is to study superheavy element chemistry, this research and techniques can be directly applied to zirconium separations in post-detonation material as zirconium is a major fission product. The speed of separations required for superheavy element chemistry is on the order of seconds. SCUREF's Tecbnical Mission Area 1 specially mentions speed accuracy and precision encerning the analysis of nuclear materials. The surrounding ligands will be all tested, beginning with TEHA. All of them have shown promise in the extraction of zirconium and hafnium in literature, but have not been fully

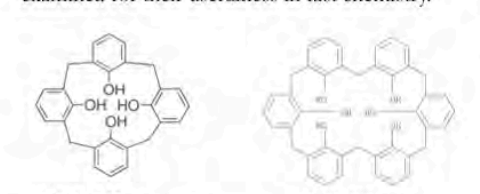

Calix[4]arene

Calix[6]arene

Thiahexa-18-crown-6
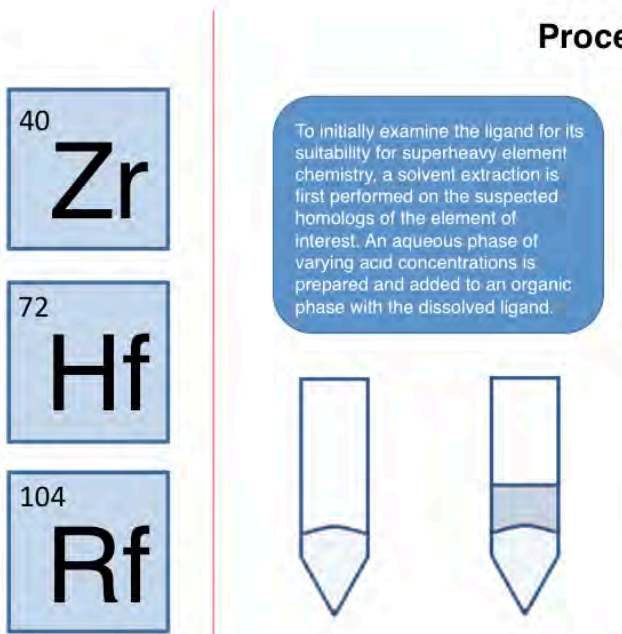

Procedure

IUniversity of Nevada, Las Vegas

${ }^{2}$ Lawrence Livermore National Laboratory

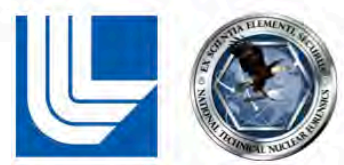

Jeff Rolfes ${ }^{1}$, John Despotopulos ${ }^{1,2}$, Roger Henderson ${ }^{2}$, Ralf Sudowe ${ }^{1}$

Dicyclohexano-18-crown-6

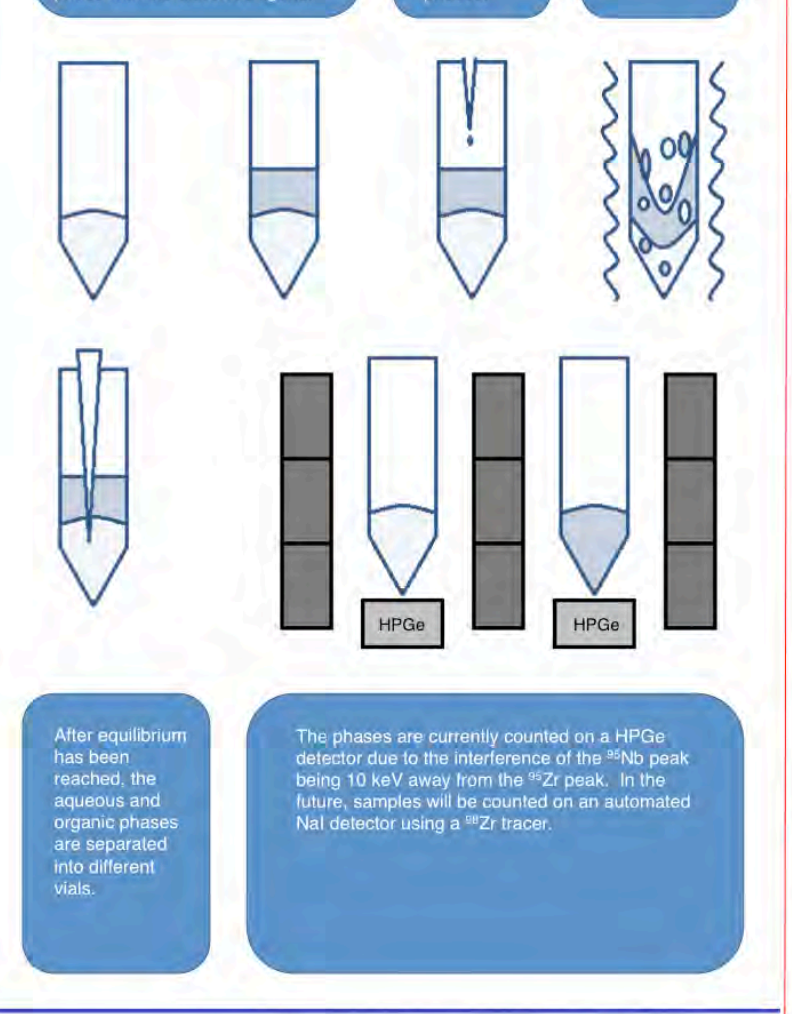

Physical and Life Sciences Directorate
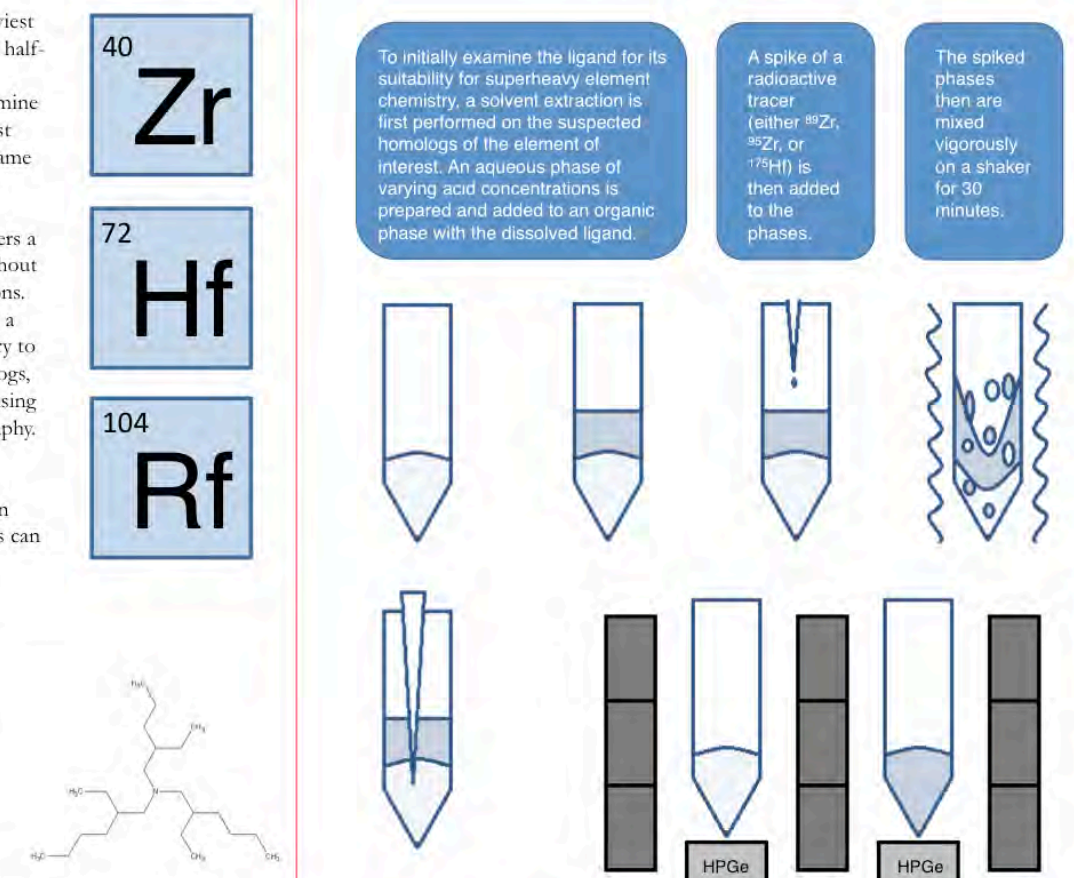

Tris-2-ethylhexyl amine (TEHA)

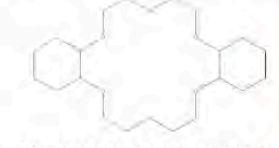

\section{Preliminary Results}

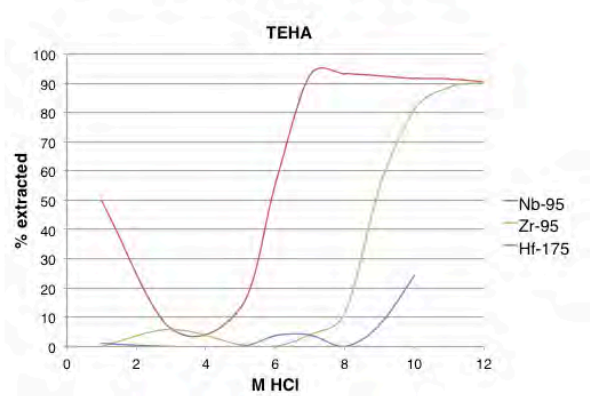

Preliminary data shows a marked separation of zirconium and hafnium. Niobium's extraction is also included as well since it is a decay product of $05 \%$ It is important to note that the ${ }^{95} \mathrm{Zr}$ used has stable carrier added to it, so its csults cannot be directly correlated to the chemical behavior of single atoms due to the amount of Zr polynuclear species formed.

\section{Goals}

For the rutherfordlum work, the new ligands mentioned will be ested using ${ }^{99} \mathrm{Zr}, 95 \mathrm{Zr}$, and $175 \mathrm{Hf}$ by performing solvent extractions with hydrochloric acid. In addition, the dicyclo-18-crown-6 will tested with nitric and sulfuric systems

f the kinetics are fast, then synthesizing a resin for extraction chromalography and conducing baich sludies witi be ine next step. rany of these extaction system appears show promise, then in zirconium and hainium. Finally, it will be applied to the study of
int zirconium and has

\section{Acknowledgements}

This matcrial is based upon works supported by the U.S. Deparment of Homeland Security under Grat

The views and conclusions contained in this document are those of the authors and should not be
interpreted as necessanly represenning the official policies, erither ceppressed or implicd, of the U.S. cent of Homeland Sccurity.

Mcpared by LLNL unde Go

\section{References}

SCUREF

1) R. Sudowe, tt al. R. Acta. 94 (2006) 123-9 2) R. Banda, ef al.J Rad Nud Clemm. (2013) 13-1 IM: LLNL.POST-641875 
Lawrence Livermore National Laboratory

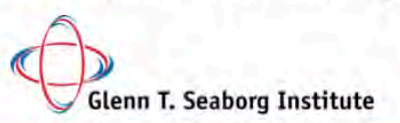

\section{Using Computed Tomography to Non-Destructively Characterize Radioactive Fallout in 3D}

Rodrigo N. Tapia, B. H. Isselhardt, K. B. Knight, J. D. Sain, I. D. Hutcheon
II

The University of Georgia

\section{Goal: Develop method to analyze 3D density distributions of fallout provided by computed tomography (CT).}

In particular, exploring the correlation of X-ray attenuation with average electron density.

\section{Overview:}

This project is divided into two main objectives: the exploration of compositional analysis by density mapping and the quantification of void spaces within fallout spheres using CT. Fallout glasses are the resulting debris formed from the rapid vaporization and condensation of ground and device materials during a nuclear detonation.

Why: Void Analysis

Rapid heating and cooling causes vesicles

Vesicles are formed by gases that do not fully evolve

Statistical distributions can help describe timeframe of formation

Why: Density Mapping

CT provides a 3D density map related to $\mathrm{X}$-ray attenuation - Greater attenuation is displayed as higher intensity

X-ray attenuation is correlated to average electron density

Average electron density is a function of density and atomic number This correlation has potential to identify compositions of interest

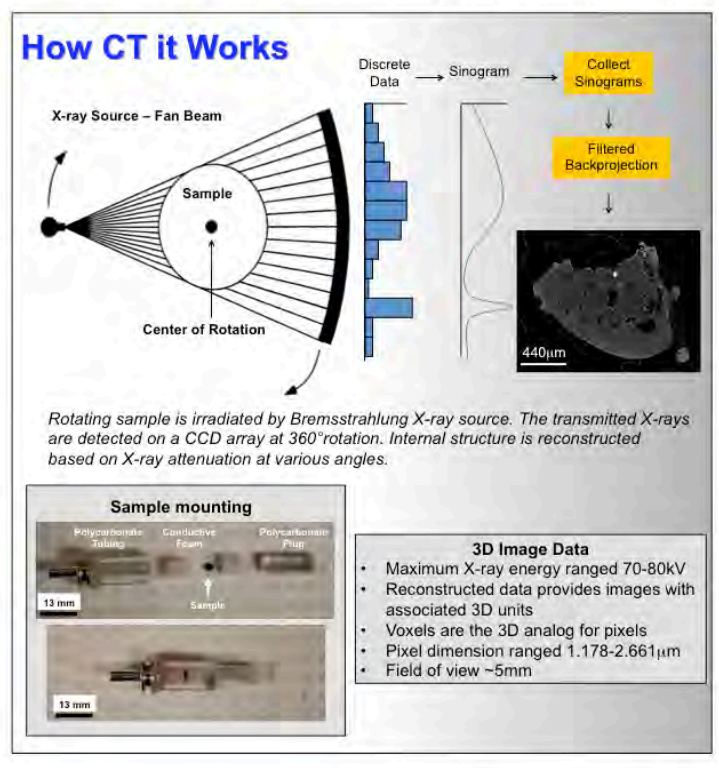

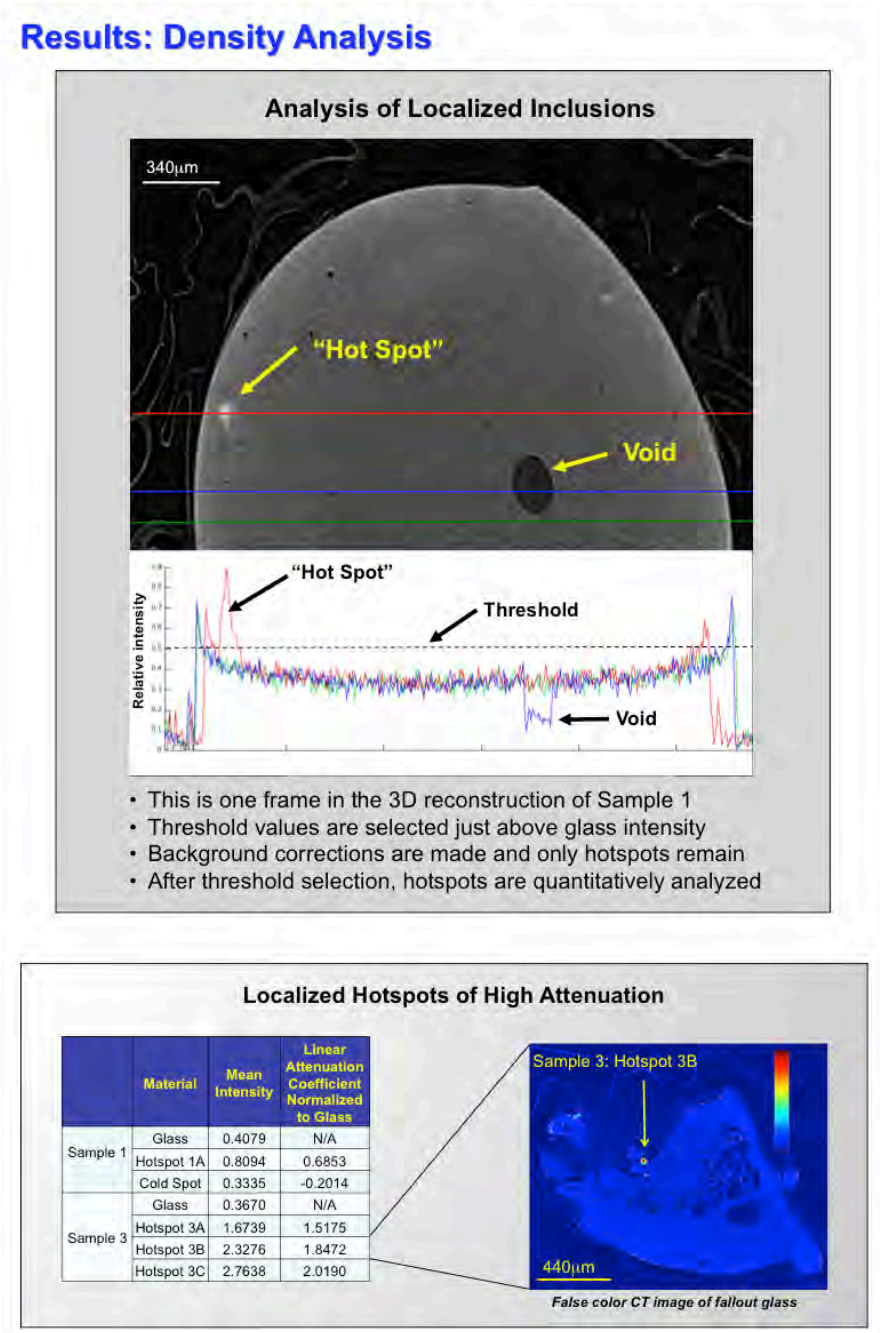

Results: Void Analysis Developed void isolation algorithm: 1. Isolated volumes of low attenuation 2. Reduced noise and established thresholds to identify voids 3. Calculated void volume and statistics

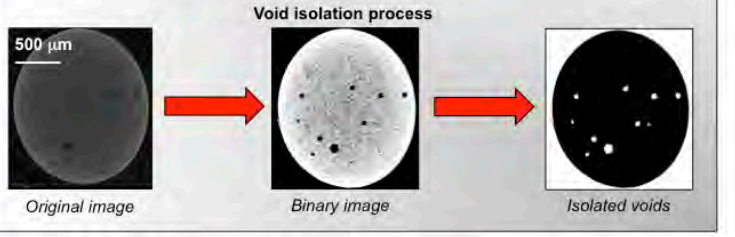

Volume Distribution of Voids

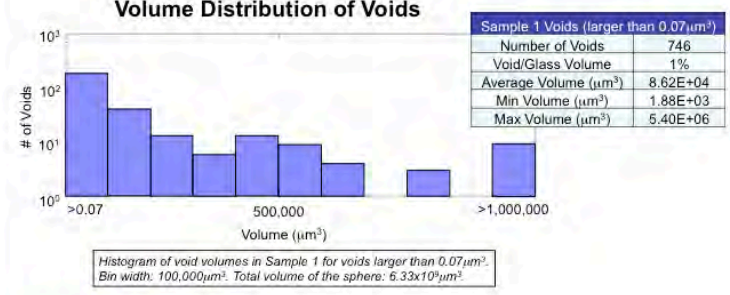

Conclusions:

- We can spatially resolve objects on the order of 10 microns

- Average electron density and X-ray attenuation are correlated

- We can locate high density inclusions in fallout

Beam hardening does not significantly impact relative intensity

- Distributions of voids may inform time-temperature sample history

Future Steps:

- Compute 3D maps of fallout features

- Perform CT analyses on 5 additional fallout samples

- Analyze a set of 4 standard metals with CT (Ta, Co, In, Al) Construct a calibration for density vs. attenuation

- Study the relationship between attenuation and composition in fallout - Analyze hotspots by scanning electron microscopy

Acknowledgements:

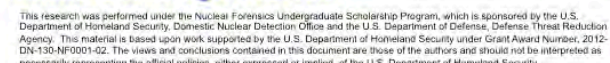

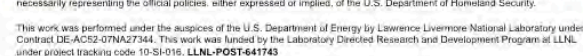

